\title{
Isolation and Characterization of Tilapia (Oreochromis mossambicus) Insulin-Like Growth Factors Gene and Proximal Promoter Region
}

\author{
JYH-YIH CHEN,,${ }^{1,2}$ HSIU-LAN TSAI ${ }^{3}$ CHI-YAO CHANG, ${ }^{2}$ JYH-I WANG, ${ }^{2}$ \\ SHIH-CHIEH SHEN, ${ }^{1}$ and JEN-LEIH WU ${ }^{2,4}$
}

\begin{abstract}
To understand the molecular mechanism which controls the transcription of the insulin-like growth factors (IGFs) gene, we have cloned and sequenced the cDNA for the proximal promoter region of the tilapia IGFs gene and have characterized its activity by chloramphenicol acetyltransferase (CAT) transient transfected expression assays. Tilapia (Oreochromis mossambicus) IGF-I cDNA (549 bp) was amplified by PCR from single-stranded cDNA of growth hormone (GH)-induced liver RNA using a pair of oligonucleotides specific for fish IGF-I as amplification primers. Tilapia $I G F-I$ and $I G F-I I 5^{\prime}$ termini were analyzed by rapid amplification of cDNA $5^{\prime}$ ends (5'RACE). Analysis of the $5^{\prime}$ RACE results revealed two transcription start sites in IGF $I$ and one transcription start site in IGF-II. Different fragments of the $5^{\prime}$ flanking region were transfected into human lung adenocarcinoma cells. In the cell line, maximum promoter activity was located in the distal 657 basepairs of the IGF-I $5^{\prime}$ flanking region and in the distal 450 basepairs of the IGF-II $5^{\prime}$ flanking region. The in vivo actions of the IGFs promoter on developmental stage expression were investigated further in transgenic zebrafish in which an IGFs promoter-driven green fluorescent protein (GFP) encoding the cDNA transgene was microinjected into embryos. Morphologic and RT-PCR studies of the transgenic zebrafish indicated that IGF-I promoter-driven GFP transcripts appeared for the first time in the 1-K-cell stage and the IGF-II promoter-driven GFP transcripts appeared for the first time in the 32-cell stage. Fluorescent (GFP) distribution was apparent within $48 \mathrm{~h}$ in IGF-II-transgenic zebrafish embryos, especially in eye, muscle, corpuscle, floor plate, horizontal myoseptum, yolk sac extension, and yolk sac. These results indicate that the IGF $I$ and $I G F-I I$ promoters are active in tissue and in a development-specific manner. Our findings also indicate that the $I G F-I I$ promoter influences the growth of fish embryos earlier than does $I G F-I$, and $I G F-I I$ has higher levels of expression than does IGF-I. These results suggest that the IGF-II promoter plays a growth factor role in teleost embryo development.
\end{abstract}

\section{INTRODUCTION}

$\mathbf{M}$ ATURE INSULIN-LIKE GROWTH FACTOR-I (IGF-I) is a single-chain polypeptide with 70 amino acid residues. It plays a central role in regulating somatic growth in all vertebrates via the modulation of growth hormone (GH) (Mathews et al., 1986). The IGF-I prepropeptide consists of S, B, C, A, $\mathrm{D}$, and $\mathrm{E}$ domains; the $\mathrm{S}$ and $\mathrm{E}$ domains are cleaved from the others during post-translational processing of the propeptide; then, the mature IGF-I is secreted into serum. In vertebrates, the effects of IGF-I on somatic growth and cell differentiation are regulated by GH and nutritional conditions (Clemmons and Underwood, 1991; Conover et al., 1993). Growth hormone increases the abundance of IGF-I mRNA by enhancing the transcription of the IGF-I gene, as well as affecting the processing of the IGF-I mRNA (Daughaday and Rotwein, 1989).

Piscine cDNA sequences have been cloned and sequenced from several species, including salmon (Cao et al., 1989;

\footnotetext{
'Institute of Zoology, National Taiwan University, Taipei, Taiwan, R.O.C.

${ }^{2}$ Institute of Zoology, Academia Sinica, Taipei, Taiwan, R.O.C.

${ }^{3}$ Institute of Toxicology, Chung Shan Medical and Dental College, Taichung, Taiwan, R.O.C.

${ }^{4}$ Institute of Fisheries Science, National Taiwan University, Taipei, Taiwan, R.O.C.
} 
Duguay et al., 1992), hagfish (Nagamasu et al., 1991), rainbow trout (Shamblott and Chen, 1992), catfish (McRory and Sherwood 1994), Sparus aurata (Duguay et al., 1996), carp (Liang et al., 1996), and tilapia (this paper), and show a high degree of homology. Fish IGF-I peptides have been conserved over the evolutionary time scale from hagfish approximately $550 \mathrm{Ma}$ to the present, suggesting that IGF-I function is important in fish. Yet fish IGF-I endocrine function and structural comparisons with mammals and birds are not understood clearly. In order to further understand comparative fish endocrine physiology, we have initiated a study of the growth regulation of IGF-I in the tilapia, Oreochromis mossambicus.

Insulin-like growth factors (IGFs) consist of two polypeptides, IGF-I and IGF-II. The peptides have high homology of protein folding structure and play important regulatory roles in growth and differentiation (Daughaday and Rotwein, 1989). Although IGFs have similar protein folding structure and growthpromotion effects, their biologic effects are mediated by different receptors. The IGF-I receptor is a tyrosine kinase receptor; the IGF-II receptor is a mannose-6-phosphate receptor (Czech, 1989). The transduction of signals operates through different mechanisms. Receptors that bind the IGFs are associated with different biologic effects in vivo and in vitro.

The $I G F-I$ gene structure has been analyzed in humans (Rotwein et al., 1986), rats (Shimatsu and Rotwein, 1987; Hall et al., 1992), sheep (Dickson et al., 1991), chickens (Kajimoto and Rotwein, 1991), and salmon (Kavsan et al., 1993, 1994). In general, the canonica fish gene consists of five exons: exon 1 encodes the $5^{\prime}$ untranslated region and part of the signal peptide; exon 2 encodes the remainder of the signal peptide and the B domain; exon 3 encodes part of the B domain, the C, A, $D$ domains, and the greater part of the $E$ domain; exon 4, a mini exon, encodes a little of the $E$ domain; while exon 5 encodes a little of the E domain and the 3 ' untranslated region. The complete mature IGF-I peptide is distributed in exons 2 and 3. Because the complicated gene structure produces multiple $\mathrm{E}$ peptides, there are many types of alternative splicing. In fish (salmon) a second nonallelic $I G F-I$ gene (designated $I G F-I .2$ ) has been found (Kavsan et al., 1994); the existence of these two alleles $(I G F-I .1$ and $I G F-I .2)$ gives rise to the multidiversity of IGF-I mRNA species, even though the salmon IGF-I gene is less than $20 \mathrm{~kb}$ in length. In salmon, the $I G F-I$ promoter region has not produced a consensus TATA box-like element, but potent stimulatory action by hepatocyte nuclear factor 1 has been found (Koval et al., 1994; Kulik et al., 1995) and may play an important regulatory role by stimulating IGF-I expression with transcription factor binding, especially of the liver-specific transcription factor. The rat promoter 1 has been shown to lack TATA and CCAAT boxes in the region 20 to 80 bp upstream of the start sites (Kim et al., 1991; Hall et al., 1992), but TATA and CCAAT-like elements are found in the major exon 2 start site (Adamo et al., 1991). The rat exon 1 and exon 2 transcripts have a tissue-specific distribution according to two promoters under different regulation. In other words, exon 1 transcripts can be detected in all rat tissue, whereas exon 2 transcripts are present in only a few tissues, particularly liver and kidney (Adamo et al., 1989, 1991).

The human $I G F-I I$ gene consists of 10 exons about $30 \mathrm{~kb}$ in length (de Pagter-Holthuizen et al., 1987, 1988; Holthuizen et al., 1990). The sequence encoding the mature, circulating 70 - amino acid polypeptides is contained within exons 8, 9, and 10 . Rat and mouse $I G F-I I$ genes consist of six exons and span about $12 \mathrm{~kb}$ of DNA (Rotwein and Hall, 1990; Ikejiri et al., 1990, 1991). The prepropeptide is also contained within exons 4,5 , and 6 . The ovine $I G F-I I$ gene is comprised of nine exons that span approximately $25 \mathrm{~kb}$, and the coding region is contained within exons 8, 9, and 10 (Ohlsen et al., 1994). The fish (tilapia) $I G F-I I$ gene has a different structure, with four exons encoding prepropeptides (Chen et al., 1997). The human IGF-II gene is controlled by four different promoters. Human promoters P2, P3, and P4 are highly activated in fetal tissue and most adult nonhepatic tissues (de Pagter-Holthuizen et al., 1988), but in adult human liver, the promoter P1 is activated, and the other promoters are not. Analysis of the human IGF-II $\mathrm{P} 4$ promoter reveals that there are three possible Spl binding sequences within $100 \mathrm{bp}$ upstream of the transcription start site. Several GC-rich regions and TATA-like sequences are contained in the human IGF-II P4 promoter region (Hyun et al., 1993). The six types of human IGF-II mRNA species are expressed by tissuespecific and development-specific pathways. The expression of these mRNA species is regulated by four promoters (de PagterHolthuizen et al., 1988) that also represent IGF-II promoters provided with tissue-specific and development-specific expression.

Little is known about promoter control of the expression of $I G F$ s during various developmental stages in teleosts; however, in Sparus aurata, IGF-I mRNA was detected in unfertilized eggs and in developing embryos (Funkenstein et al., 1996). Onchorynchus mykiss mRNA is maternally stored in eggs and was detected from the cleavage stage to the feeding stage (Greene and Chen, 1997). These data indicate that IGFs play an important role in embryonic development. However, up to now, no reports have been published concerning which $I G F-I$ or IGF-II promoter plays what role in the development of fish.

Recently, we isolated and sequenced the tilapia $I G F-I$ and $I G F-I I$ cDNA, expressed the recombinant polypeptides in an $E$. coli system, and characterized the structure of the IGF-II coding region (Chen et al., 1997). Our main objective in this paper is to describe the characterization of the proximal promoter regions of tilapia $I G F-I$ and $I G F-I I$ genes. We have used not only the chloramphenicol acetyltransferase (CAT) system to analyze the proximal promoter activity but also the green fluorescent protein (GFP) system to analyze the proximal promoter features of tissue-specific and development-specific expression. The results indicate that the $I G F-I$ and $I G F-I I$ proximal promoters are important regulators of embryonic growth and development.

\section{MATERIALS AND METHODS}

\section{Oligonucleotides}

The PCR primers for cloning IGF-I cDNA are located on the $\mathrm{S}$ and $\mathrm{E}$ domain regions. After comparing several fish $I G F$ $I$ sequences, two universal primers were designed, namely, IGFI primer 1 and IGF-I primer 2 . The 5 ' end of these primers contains the EcoRI restriction site. For $I G F-I$ genomic DNA cloning, six primers were designed to amplify the coding region, namely IGF-I exon primers 1 through 6 . As for first-strand 
TABle 1. Primers Used

\begin{tabular}{|c|c|}
\hline Name & Sequence $^{\mathbf{a}}$ \\
\hline IGF-I primer1 & 5'-CGGAATTCATGGAAACCCAGCAAAGATAC \\
\hline IGF-I primer2 & 5'-CGGAATTCTCATTTTGTGACTGACAAAGTTG \\
\hline IGF-I exon primer1 & 5'-CGAAGCTTAGATCMAAATTCRAKCCYATTC \\
\hline IGF-I exon primer2 & 5'-GTCTCGAGTTGTTTTTACAGTGAACCATTCC \\
\hline IGF-I exon primer3 & 5'-CGGGATCCGAAATAAAAGCCTCGCTCTCCACAGA \\
\hline IGF-I exon primer 4 & 5'-CGGGATCCAATAAACCCAACAGGCTATGGCCCCAGT \\
\hline IGF-I exon primer 5 & 5'-CGGAATTCGGCCCTGAGACCCTGTGCGGG \\
\hline IGF-I exon primer6 & 5'-CGGAATTCAGAAATCTTGGGAGTCTTGAC \\
\hline IGF-I GSP1 & 5'-CGCTCGAGCGCCCCTGTTGCCGTCGGAG \\
\hline IGF-II GSPI & 5'-GGTTGGCCTACTGAAATAAAA \\
\hline IGF-I P2 primer & 5'-CGAAGCTTATTTTTACATTTTCACTC \\
\hline IGF-I P3 primer & 5'-CGAAGCTTCGGTGCCAAATTACGCAC \\
\hline IGF-I P4 primer & 5'-CGCTGCAGGACATTTTCAACAGGAAA \\
\hline IGF-I P5 primer & 5'-CGAAGCTTGCTGGTGGTGGTGGTGGGGCTG \\
\hline IGF-I P6 primer & 5'-CGCTGCAGGACTTTGTTCCATTGCGC \\
\hline IGF-I P7 primer & 5'-CCCTGCAGTTCCAACAAGACAAAGC \\
\hline IGF-II P3 primer & 5'-GGAAGCTTCATGCCTGCATCTAC \\
\hline IGF-II P4 primer & 5'-GGAAGCTTCTGCATCAACCCCG \\
\hline IGF-II P5 primer & 5'-GGAAGCTTAGTGATTCCACTG \\
\hline IGF-II P6 primer & 5'-GGAAGCTTCATTTTTCTTGGAGTC \\
\hline IGF-II P7 primer & 5'-CGCTGCAGCCTGTGTGTAAACATTGTGA \\
\hline IGF-II P8 primer & 5'-GGAAGCTTTGCCCATGGAAGTGTTC \\
\hline IGF-II P9 primer & 5'-CGCTGCAGTTCAAGCACTTTCATAAAAC \\
\hline IGF-II P11 primer & 5'-GCGTCGACGTCAGATGGCAGTAGTCAAAATG \\
\hline GFP1 & 5'-TTCACCGGGGTGGTGCCCATCCTGGTC \\
\hline GFP2 & 5'-TTGAAGAAGATGGTGCGCTCCTGGACGTAGC \\
\hline
\end{tabular}

${ }^{\mathrm{a}} \mathrm{W}=\mathrm{A}$ or $\mathrm{T} ; \mathrm{Y}=\mathrm{C}$ or $\mathrm{T} ; \mathrm{K}=\mathrm{G}$ or $\mathrm{T} ; \mathrm{S}=\mathrm{C}$ or $\mathrm{G} ; \mathrm{M}=\mathrm{A}$ or $\mathrm{C} ; \mathrm{R}=\mathrm{A}$ or $\mathrm{G}$.

cDNA synthesis for rapid amplification of 5'cDNA ends, two primers were designed, namely, IGF-I GSP1 and IGF-II GSP1. For IGF-I promoter assay, six primers were designed to amplify the promoter region, namely, IGF-I P2 through IGF-I P7. For IGF-II promoter assay, seven primers were designed to amplify the IGF-II promoter region, namely IGF-II P3 through IGF-II P9 and IGF-II P11. For checking GFP expression, two primers were designed to amplify that coding region, namely GFP 1 and GFP 2. The sequences of all primers are shown in Table 1; they were synthesized by Quality Systems, Inc., Taiwan.

\section{Isolation of total RNA}

Tilapia (Oreochromis mossambicus) were obtained from the Tainan Fishery Institute and maintained in plastic tanks $2 \mathrm{~m}$ in diameter under constant photoperiod ( $13 \mathrm{~h}$ light:11 h dark) at $23^{\circ} \mathrm{C}$. In order to obtain high levels of IGF-I RNA, the fish were injected at $8 \mathrm{~h}$ intervals with yellowfin porgy (Acanthopagrus latus) GH (Tsai et al., 1993) at a dose of $1 \mu \mathrm{g} / \mathrm{g}$ of body weight for three doses. Total liver RNA was prepared by the guanidinium-phenol-chloroform extraction method (Chomczynski and Sacchi, 1987).

\section{Reverse transcription and PCR assay}

First-strand cDNA was generated from $30 \mu \mathrm{g}$ of total RNA in a $37 \mu$ reaction volume. The IGF-I primer 2 was then added, incubated at $80^{\circ} \mathrm{C}$ for $10 \mathrm{~min}$, and allowed to cool down slowly to room temperature in order to anneal the IGF-I primers to the corresponding cDNA. This sample was mixed with $5 \mu \mathrm{l}$ of $10 \times$ first-strand buffer (Stratagene), $2 \mu \mathrm{l}$ of $100 \mathrm{mM}$ dNTPs (Stratagene), and $2 \mu \mathrm{l}$ of SuperScript ${ }^{\mathrm{TM}}$ II RNase $\mathrm{H}^{-}$reverse transcriptase (200 U/ $\mu \mathrm{l}$; GIBCO BRL). Next, the cDNA synthesis mixture was incubated at $42^{\circ} \mathrm{C}$ for $60 \mathrm{~min}$ and then at $95^{\circ} \mathrm{C}$ for $5 \mathrm{~min}$. After incubation, the reaction vessel was immediately placed on ice. The PCR reaction was carried out in a final volume of $100 \mu l$. The reaction was constituted by the first-strand cDNA, $10 \mu \mathrm{l}$ of $10 \times$ PCR buffer (HT Biotechnology), $200 \mu \mathrm{M}$ of each dNTP, $1 \mu \mathrm{g}$ of IGF-I primer 1 and primer 2, and 2.5 units of Taq DNA polymerase. The reaction mixture was subjected to $35 \mathrm{PCR}$ cycles of $1 \mathrm{~min}$ at $94^{\circ} \mathrm{C}$ (denaturation), $2 \mathrm{~min}$ at $42^{\circ} \mathrm{C}$ (annealing), and $2 \mathrm{~min}$ at $72^{\circ} \mathrm{C}$ (extension); the PCR products were then resolved on $2 \%$ agarose gel.

\section{PCR product cloning, sequencing, and analysis}

The PCR products were size-separated by gel electrophoresis and digested with EcoRI. The digested product of the predicted size ( $549 \mathrm{bp}$ ) was then subcloned into the pUC18 plasmid using $5 \mathrm{U}$ of T4 DNA ligase (BM). The recombinant plasmid was transformed into the $E$. coli JM109 strain. The nucleotide sequences of each insert were determined by the dideoxynucleotide chain termination method (Sanger et al., 1992) using forward and reverse primers. The comparison of 
the predicted $I G F-I$ nucleic acid sequences and predicted amino acid sequences was performed using the Genetics Computer Group Gap program. To compare and align these sequences with those which have been published, we introduced gaps to maximize identity via procedures described by the Gap program (Higgins and Sharp, 1988) and Molecular Evolutionary Genetics Analysis (Kumar et al., 1993).

\section{Isolation and Characterization of Tilapia IGFs Genes}

Approximately 1 million recombinant bacteriophages from the tilapia genomic DNA library were screened with ${ }^{32} \mathrm{P}$-labeled $I G F-I$ 549-bp PCR fragments. This DNA library was constructed in a phage charon 40 vector. The hybridization buffer used was $50 \%$ formamide containing SDS $(7 \mathrm{~g} / 100 \mathrm{ml}), 0.5 \mathrm{M}$ EDTA (pH 8.0, $100 \mu \mathrm{l} / 100 \mathrm{ml}), 50 \%$ PEG8000 (20 ml/100 ml), and formamide $(50 \mathrm{ml} / 100 \mathrm{ml})$ at $42^{\circ} \mathrm{C}$ for $16 \mathrm{~h}$; after hybridization, filters were washed in four times with $0.1 \times \mathrm{SSC}$ and $0.1 \%$ SDS at $65^{\circ} \mathrm{C}$. A total of 18 positive plaques were obtained. Exon primers 1 and 3 were used for PCR to amplify $I G F-I$ exons 1 and 2; exon primers 2 and 4 were used to amplify $I G F-I$ exons 3 and 4 ; and exon primers 5 and 6 were used to amplify the $I G F-I$ intron between exons 2 and 3 . The PCR was performed with $10-\mu 1$ positive phage plaque solutions containing $10 \mu \mathrm{l}$ of $10 \times$ extension buffer, $8 \mu \mathrm{l}$ of $2.5 \mathrm{mM} \mathrm{dNTP}$, $1 \mu \mathrm{g}$ of each primer, $\mathrm{ddH}_{2} \mathrm{O}$, and 2.5 units of Taq polymerase (TakaRa LA Taq ${ }^{\mathrm{TM}}$, Japan). The PCR was performed in a thermal cycler (Perkin Elmer-Cetus 2400) for 35 cycles with denaturation at $94^{\circ} \mathrm{C}$ for $1 \mathrm{~min}$, annealing at $50^{\circ} \mathrm{C}$ for $1 \mathrm{~min}$, and extension at $72^{\circ} \mathrm{C}$ for $5 \mathrm{~min}$. Ten microliters of PCR products was analyzed by electrophoresis on $0.9 \%$ agarose gels. After ethidium bromide staining, DNA fragments of the predicted size (exon primers 1 and 3 amplified about $1.9 \mathrm{~kb}$, exon primers 2 and 4 about $3.2 \mathrm{~kb}$, and exon primers 5 and 6 about $11 \mathrm{~kb}$ ) were excised from the agarose gel, and the QIAquick gel extraction kit (QIAGEN GmbH and QIAGEN Inc.) was used to extract the DNA. The PCR products were sequenced by an ABI autosequencer. The nucleic acid sequences were compared with the Genetics Computer Group Gap computer program. In another way of doing this, we isolated one of the $I G F-I$ genomic clones, mapped by restriction endonuclease, and subcloned the DNA fragments. These clones contain the $1.3 \mathrm{~kb}$ of nucleotides encoding the promoter region.

For $I G F-I I$ gene structure and promoter region determination, we continued to sequence the recombinant bacteriophage

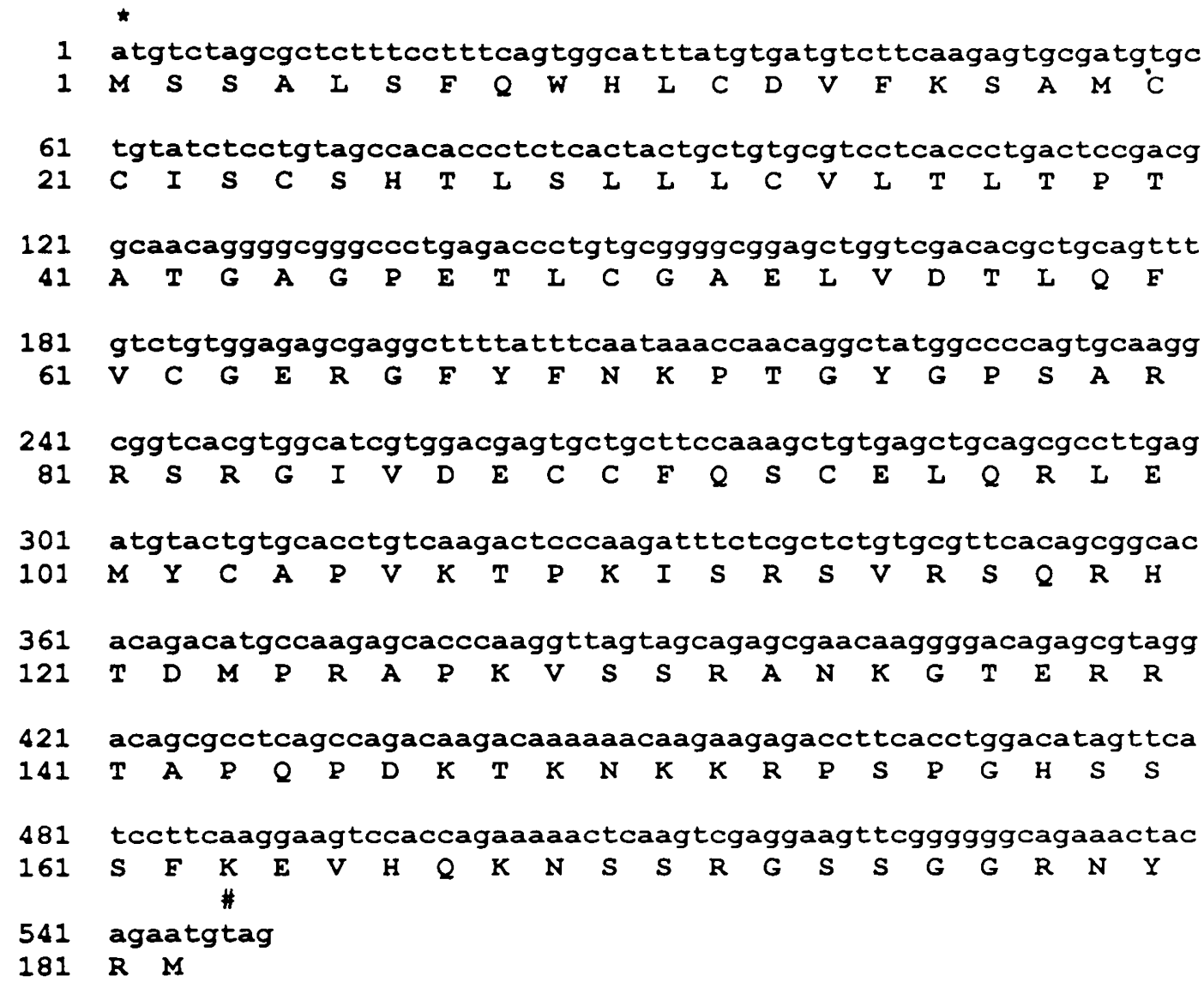

FIG. 1. Nucleotide sequence of $I G F-I$ cDNA isolated from Oreochromis mossambicus. Predicted amino acid sequence is shown below. Numbers on second line of each row represent amino acid position. Tilapia sequence contains a signal peptide (132 nt; 44 amino acids, 1 to 44 ), B domain ( $87 \mathrm{nt} ; 29$ amino acids, 45 to 73 ), C domain ( $27 \mathrm{nt} ; 9$ amino acids, 74 to 82 ), A domain (66 nt; 22 amino acids, 83 to 105), D domain ( 24 nt; 8 amino acids, 106 to 113 ), and E domain (210 nt; 70 amino acids, 114 to 183 ). Tilapia $I G F-I$ cDNA insert contains $549 \mathrm{nt}$, which encode 183 amino acid residues. ${ }^{*}=$ codon; \# = stop codon. 
clone (Chen et al., 1997), subcloning the DNA fragments and sequencing the upstream ATG (start codon) of approximately $5.7 \mathrm{~kb}$ and the downstream TGA (stop codon) of approximately $3.4 \mathrm{~kb}$.

\section{RNA isolation and rapid amplification of $5^{\prime}$ CDNA ends (5'RACE)}

Total RNA was isolated from tilapia liver. The RNA extraction method followed the manufacturer's protocols (ULTRASPEC $^{\mathrm{TM}}$-II RNA isolation system; Biotecx Laboratories, Inc., U.S.A.). The 5'RACE procedure (Peduel et al., 1994) strictly followed the instruction manual (Life Technologies, U.S.A.) and Frohman (1990, 1993). Briefly, the sample contained about $5 \mu \mathrm{g}$ of total RNA, and either the IGF-I GSP1 or the IGF-II GSP1 primer. After PCR, the $5^{\prime}$ RACE products were analyzed on $1.5 \%$ agarose gel and transferred to nylon membranes (BioRad). The membranes were probed separately with [32P] dCTP-radiolabeled $I G F-I$ P2 $\rightarrow$ P7 genomic DNA fragments and $I G F-I I \mathrm{P} 3 \rightarrow \mathrm{P} 11$ genomic DNA fragments. The hybridization procedure was the same as that described above for the isolation and characterization of the tilapia IGFs gene. Af- ter verifying which fragments hybridized with the probe, restriction endonuclease-digested 5'RACE products were cloned into the pBluescript plasmid vector (Strategene) and sequenced to confirm the genomic sequence.

IGF promoter plasmid constructs, cell culture, and transient transfection assays

An approximately $2 \mathrm{~kb}$ SacI-SacI fragment was obtained from an Oreochromis mossambicas IGF-I genomic clone. This fragment includes 1360 bp of the $5^{\prime}$ flanking region and the transcription start site sequence. The promoter activity assay of fragments was amplified by PCR (The primer location is referenced below in Fig. 3 and Table 1). The PCR product was digested with PstI and HindIII restriction endonucleases, and the fragment was ligated into the HindIII and PstI sites of the pCAT-Basic vector (Promega). The pCAT-Basic vector is a promoterless plasmid containing multiple cloning sites upstream of a CAT cDNA. This resulted in the $I G F-I$ promoter activity assay obtaining seven construct plasmids (see Fig. 6). The clones of IGF-I P2 $\rightarrow$ P7, IGF-I P3 $\rightarrow$ P6, IGF-I P3 $\rightarrow$ P7, IGF-I P5 $\rightarrow$ P6, and IGF-I P5 $\rightarrow$ P7 were constructed and con-

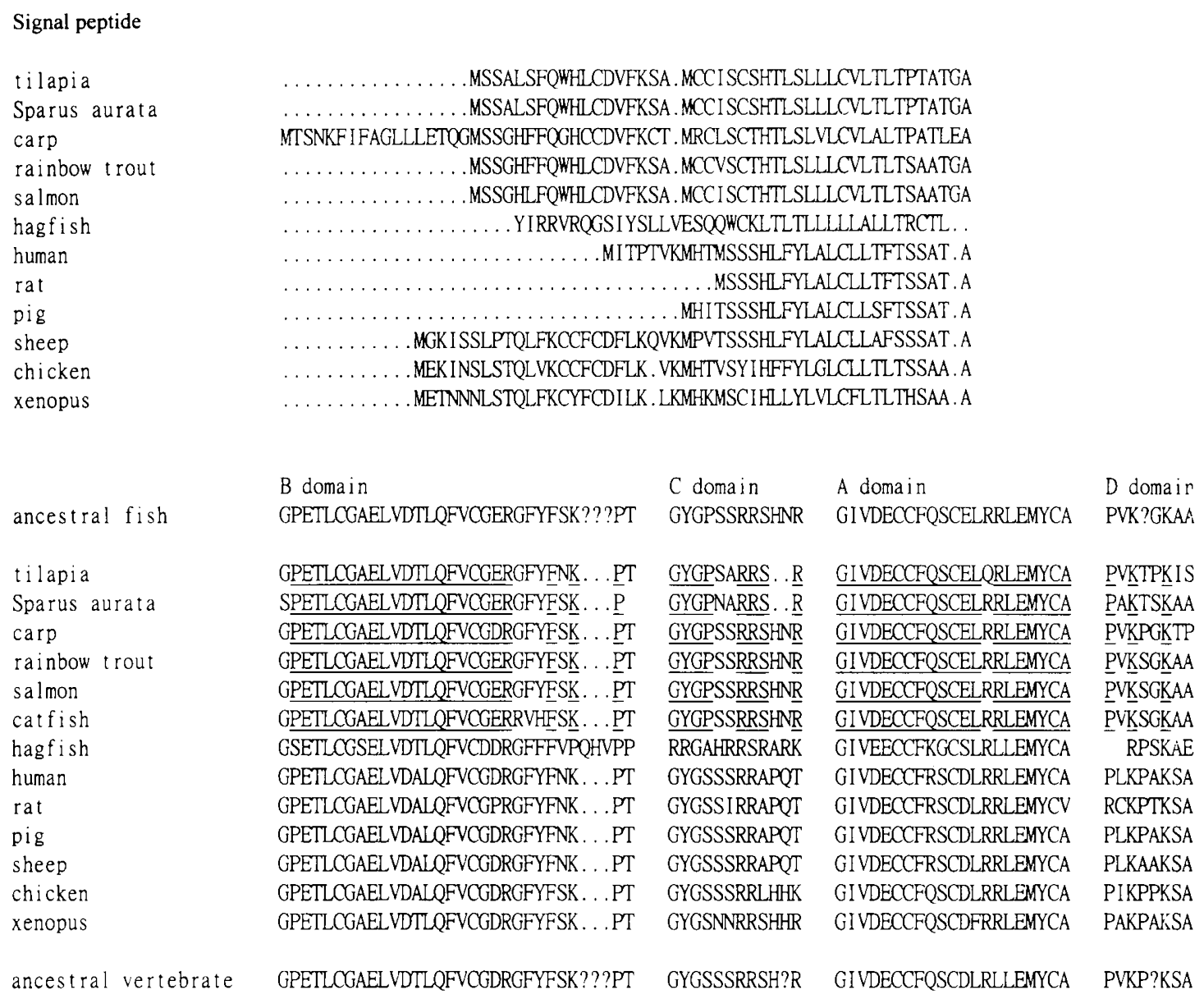

FIG. 2. Comparison of amino acid sequences of IGF-I in tilapia, Sparus aurata, carp, salmon, rainbow trout, catfish, hagfish, human, rat, pig, sheep, chicken, and Xenopus. Gaps (...) were introduced to maximize potential homologies. Hypothetical ancestral piscine IGF-I sequence is shown above; hypothetical ancestral vertebrate IGF-I sequence is shown below. Mature peptides largely conserved in all fish are underlined. There are four types of amino acid sequences in IGF-I E domain; herein, we do not compare them because of the complexity of this region. Amino acid sequences of.F-Y-F are putative receptor binding site in B domain. 
tain two transcription start sites. The clones IGF-I P3 $\rightarrow$ P4 and IGF-I P5 $\rightarrow$ P4 lack one transcription start site, that connected immediately upstream of the ATG codon.

Fragments of the IGF-II gene containing the promoter region were obtained from the Oreochromis mossambicas genomic clone. The IGF-I and IGF-II transcription start site was dependent on the 5'RACE result and assigned at -1 to be near the first nucleotide upstream of the ATG codon, with the definition of the -1 number according to Koval et al. (1994). The deletion series of the $I G F-I I$ promoter was constructed by PCR amplification using oligonucleotides designed to generate ends with PstI-SalI and HindIII-SalI restriction sites. This resulted in the $I G F-I I$ promoter activity assay obtaining eight construct plasmids (see Fig. 6). The PCR products of IGF-II P3 $\rightarrow$ P11, IGF-II P4 $\rightarrow$ P11, IGF-II P5 $\rightarrow$ P11, IGF-II P6 $\rightarrow$ P11, IGF-II $\mathrm{P} 7 \rightarrow \mathrm{P} 11$, IGF-II P9 $\rightarrow \mathrm{P} 11$, IGF-II P7 $\leftarrow \mathrm{P} 11$, and IGF-II $\mathrm{P} 8 \leftarrow \mathrm{P} 11$ were then cloned into the pCAT-Basic vector, after which the pCAT-Basic vector was digested with the same enzymes. Next, the QIAGEN plasmid extraction maxi kit was used to extract DNA, and one strand was processed by an ABI autosequencer to identify the orientation and sequence.

Human lung large cell carcinoma cells (ATCC NCI H1299) were grown in DMEM (glucose $4.5 \mathrm{~g} / \mathrm{l}$ ) containing $10 \%$ newborn calf serum. Approximately $6 \times 10^{5}$ cells were seeded 12 $\mathrm{h}$ before transfection. Calcium phosphate-mediated DNA transfection was as described previously (Tsai et al., 1996). Typically, the transfection lasted $12 \mathrm{~h}$. The CAT activity was measured $48 \mathrm{~h}$ after transfection and quantified as described previously (Tsai et al., 1996). Plasmids of pEGFP-1 ligated with a $I G F s$ promoter region were transfected into the same cells. The procedure is described below, and the transfection method was the same as that used for the CAT assay.

Reporter gene constructs, preparation of plasmid DNA, fish egg collection, and microinjection

The vector of pEGFP-1 (CLONTECH Laboratories, Inc.; the pEGFP-1 vector sequence can be found in GenBank accession number U55761) was constructed by inserting IGF-I P2 $\rightarrow$ P7 as a HindIII-PstI site from the PCR fragment; the insertion of the IGF-II P5 $\rightarrow$ P11 PCR fragment was conducted with the
pEGFP-1 vector as a HindIII-Sall site. Plasmid DNA was extracted according to the QIAGEN handbook for the plasmid maxi kit (QIAGEN GmbH and QIAGEN Inc.). After purification, the plasmids were precipiated using ethanol and sodium acetate. The DNA pellet was resuspended in $\mathrm{ddH}_{2} \mathrm{O}$ and stored at $-20^{\circ} \mathrm{C}$.

The experimental specimens of Brachydanio rerio (zebrafish) were maintained under standard conditions with an artificial photoperiod of $11 \mathrm{~h}$ of darkness to $13 \mathrm{~h}$ of light to induce and maintain the reproductive cycle. Fertilized eggs were collected, and one of the two cells in the embryo was intracytoplasmically with an appropriate amount of supercoiled plasmid DNA $100 \mu \mathrm{g} / \mathrm{ml}$. The injection method and GFP assay procedure are described in Winkler et al. (1991) and Amsterdam et al. $(1995,1996)$.

\section{Fluorescence microscopy observation and RT-PCR}

After injection of supercoiled plasmid DNA (the construction plasmid of pEGFP-1 vector ligated with the IGF-I or IGF-II promoter region) into the zebrafish embryos, eggs were kept in a $28^{\circ} \mathrm{C}$ incubator. Embryos were observed and photographed on an Olympus microscope IX70 and Leica MPS 48/52 dissection microscope with a fluorescence filter using a long-wave UV lamp.

The zebrafish embryo RNA extraction method was according to the manufacturer's protocols (ULTRASPEC ${ }^{\mathrm{TM}}$-II RNA isolation system; Biotecx). For IGFs promoter assay, 10 onewk-old fish (for $I G F-I$ promoter assay) and 10 two-wk-old fish (for IGF-II promoter assay) were collected, and their respective extractions were pooled. These embryos and fish were all injected with the construction of pEGFP-1 vector ligated with the $I G F-I$ or $I G F-I I$ promoter region as described above. The concentration of total RNA was measured by an ultraviolet spectrophotometer at an absorbance of $260 \mathrm{~nm}$.

In order to investigate whether the expression of IGFs promoters is stage or tissue specific, $1.6 \mu \mathrm{g}$ of whole embryo or fish total RNA and the GFP 1 and GFP 2 primers were put together in one-tube mixtures and used to amplify internal fragments of GFP first-strand cDNA. The PCR was run continuously to amplify about 317 bp of the GFP coding region according to the manufacturer's instructions (AMPLY RT/PCR

Table 2. Homology of Insulin-Like Growth Factor (IGF) PolypePtidE ${ }^{a}$

\begin{tabular}{|c|c|c|}
\hline $\begin{array}{l}\text { Insulin-Like } \\
\text { Growth Facator }\end{array}$ & $\begin{array}{c}\text { Tilapia IGF-I } \\
\text { Mature Peptide } \\
\text { Identity (\%) }\end{array}$ & References \\
\hline Tilapia IGF-II & 59.1 & Chen et al., 1997 \\
\hline Catfish IGF-I & 83.8 & McRory and Sherwood 1994 \\
\hline Hagfish IGF-I & 59.7 & Nagamasu et al., 1991 \\
\hline Human IGF-I & 79.4 & Rindernecht and Humbel, 1978; Klapper et al., 1983 \\
\hline Mouse IGF-I & 79.4 & Bell et al., 1986 \\
\hline Pig IGF-I & 79.4 & Tavakkol et al., 1988; Muller and Brem, 1990 \\
\hline Rainbow trout IGF-I & 86.8 & Shamblott and Chen, 1992 \\
\hline Rat IGF-I & 79.4 & Roberts et al., 1987 \\
\hline Salmon IGF-I & 89.7 & Cao et al., 1989; Duguay et al., 1992 \\
\hline Sheep IGF-I & 79.4 & Wong et al., 1989 \\
\hline
\end{tabular}

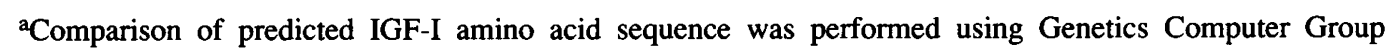
program. 
Tilapia IGF-I Exon 1 and promoter region

- 1213 GAGCTCCIGTATCGGAAGCGTGTGTCAGTGCTGCTGCCTGTGACATTTGA - 1163 TGATGATCGCGTTTTGACCCACTTTACCCAAACAACTCTAACTGTTGCGT - 1113 GTCTTAAGTCCCCTTTGGAACCAACCTTGCTCGTGATGCACACACACAAA - 1063 CACGGACGGAGCATGCCTGGATACGTGCCGGTGTCCTGTTTTATGATTGG - 1013 GTCACAGCACTGATCTCATGTTTAGTGACTGGATCAGTGTTGATATCCCA -963 TCACTGCTGAGAACAACCCTCTTTAAGCCCTTGCTTTCGTCCCTTCCTGT -913 GACACAGTGGGAACTGCGGGGCCCCGACTTCAACACGATGACAGTGGGTG -863 GGCCTGCATCAAGAGTCTGTCAGTGCAAAACAATGGCTCCAGGAATTGAA -813 ATTAATGTCTCCTCCATCATAAAACCCCATGTGTTTTTCTTTTTTTCCTC

- 763 CTTTTTTTATTTTTCCACTCTAGTTCACAGGNGCATCAGATGTCATTTAC

-713 AGCCGAACCCACTTCTATTAAGTGAAAATCAGCAAGAAGGGAGAGAAAAC

-663 CAGAGACATACACCAGGNTTATGCAGTGACAGTGTGCAGAAAGGCAGCAA

-613 ACCCTGCACAGTGGCTCTCAGTTTAGAGGGAACAGGGCTTCACATGTGGC

-563 TTTCTGGCTCAAGTTTGCTCCTTACTGTAATAAAAATGTCACATTTTTAC

$-513 \stackrel{\text { ATTTTCACTCCAGTTCACATTTATTTAGCTTTTCCTIGTGAGGTTTTCAG }}{\longrightarrow}$ P2 Primer

-463 GTGAGGAGCACTGCGGCGTCTAAGTGGGAAAGTGTTTTTAATGATTTATT

-413 TAATCAAACCATTAGTGGAGAGACTTGGTGGTCAGATACACGGTGCCAAA

-363 $\stackrel{\text { TTACGCACAACAGCAAAGAGCCATATCACAACCGCCAGCTCGTCTTTAC }}{\longrightarrow}$ P3 Primer

-313 TTCTCCTTTATGAGCGTTTCAGGGCACAAAATAATGCGTTTGTAAGAGTG

-263 TGAGCCGCCACTGCTGCTGCTGGTGGTGGTGGTGGGGCTGATCTGAACTA P5 primer

-213 CTAACCAAGTCTTAGAGAGATCAAAATTCAATCCCGTTCTGAGAAAAAAC

- 163 AGAAATGACGT TATTTGAATATGTGCCCAAAATCCTTAATGAATAACTTA HNF 5-like HNF 1-like

5'RACE

- 113 GGACGAGTAGGAGGCAAATGCTGCCCCAGCTGTTTCCTGTIGAAAATGTC P4 Primer

-63 TGTGTAATGTAGA'IAAATGTGAGGGATTTTCTCTCTAAATCCGTCTCCTG

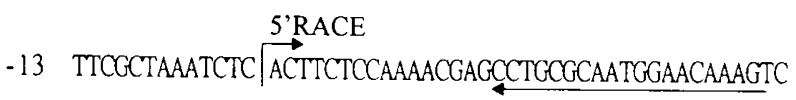
P6 Primer

38 GGAATATTGAGATGTGACATTGCCCGCATCTCATCCTCTTTCTCCCTGTT

88 TTTAATGACTTTAAACAAGTTCATTTTCGTCGGGCTTTGTCTTGTTGGAA *

138 AACCGTGGGGATGTCTAGCGCTTTTTCCTTTCAGTGGCATTTATGTGATG

188 TCTTCAAGg taact t acc tgat $t$ tcct $t$ tgacact a tacat t a t cacct $t$

238 gat tcttcact tgctcactat tgcacagagcatcctcgcetact taaa 288 aagaaacaataaaggggat $t c t$ tatcgct tgct tgtat $t$ tcacagct $t$
338 tgaacgcatgcat tggtgcggat tat tcacat t t tctcctt tcatcc 388 act tatggaacaactctccocatgtcctggtaatctatt tatt tat 438 ttatt tccagagataat tat t t tctacat t tgct taat tgat tct 488 tt tctcttttgcaat taaaaaaaatcat tgacatggatcgtgcatga 538 ct t tcagcgcagg ta tgaat t tggacat t t tccgt gcgcccggcgctct t 588 tt tccaccagaagcctaatgcagctgtgcaact t tccaaag taat tac 638 tgctgagtctgcataat t taagt tgctaatatctaacctgatgcctctgg 688 cggggt tgaaagaacgagagcgggagagagagagat ttccgaacact tg 738 cgggcgtcgggaact tgcgggtgtgaag t taa tagataacg tcccggt t $788 \mathrm{t}$

\section{Tilapia IGF-I Exon 2}

1 gttaaagaaactcttttccgatgatgctgtgaaaatgt tct tgctctc 51 tcccetgtgcgcagAGTGCGATGTGCTGTATCTCCTGTAGCCACACCCTC 101 TCACTACTGCTGTGCGTCCTCACCCTGACTCCGACGCCAACAGGGGCGGG 151 CCCTGAGACCCTGTGCGGGGCGGAGCIGGTCGACACGCTGCAGTTTGTCT 201 GTGGAGAGCGAGGCTTTTATTTC......

\section{Tilapia IGF-I Exon 3 and Exon 4}

1

51 GGACGAGTGCTGCTTCCAAAGCIGTGAGCTGCAGCGCCTTGAGATGTACT

101 GTGCACCTGTCAAGACTCCCAAGATTTCTCGCTCTGTGCGTTCACAGCGG

151 CACACAGACATGCCAAGAGCACCCAAGGTTAGTAGCAGAGCGAACAAGGO

201 GACAGAGCGTAGGACAGCGCCTCAGCCAGACAAGACAAAAAACAAGAAGg

251 t tgagctaagcatcaaaacaga taaactg taaaaat tgt tgat tggatcg

301 aat tacatt tctgttacatgatcagagcat acgtgcataatatcctgat

351 taat taaggtgatatagct taataagcagaaactcgtccatccaactaaa

401 gt tacctaat $t$ t tct tccacagAGACCTTCACCTGGACATAGTTCATCC

451 TTCAAGgtatgcatgcaaatgatctcatgt tcattgtcctttgtcatt

501 taagctttaccaaaacacacaatctctcccatgacataagagt t tcaaag

551 caggcgatctttacagaa

\section{Tilapia IGF-I Exon 5}

1 tctatatctctgctgtacatctaaaaaaaaaaaaaaaaaaacaaatgt 51 gt $t$ t tat $t \mathrm{t} t \mathrm{t} t \mathrm{tgcagGAAGTCCACCAGAAAAACTCAAGTCGAGGAAG}$ \#

101 TTCGGGGGGCAGAAACTACAGAATGTAGGGAGGAACAAATGGACAAATG 151 CCCAGCAATTGGGAGGAGAGAAGGGAGTGCCCTTACCTGGTNACCCTGTG 201 GAATGGTTCACTGTAAAACAA

FIG. 3. Partial nucleotide sequence of IGF-I genomic DNA isolated from Oreochromis mossambicus. Tilapia IGF-I exon sequences and $5^{\prime}$ flanking sequences are shown in uppercase letters; intronic sequences are shown in lowercase letters. \# = stop codon; ${ }^{*}=$ start codon. Numbered arrows under sequence indicate positions for CAT assay of PCR-constructed primer. Regions of 5'RACE termini are marked by arrows above sequence and labeled 5'RACE.

Kit; LTK BioLaboratories, R.O.C.). The amplification program was established for a Perkin-Elmer 2400 thermocycler and was as follows: 1 cycle of $5 \mathrm{~min}$ at $60^{\circ} \mathrm{C}, 30 \mathrm{~min}$ at $42^{\circ} \mathrm{C}, 35 \mathrm{cy}$ cles of $1 \mathrm{~min}$ at $94^{\circ} \mathrm{C}, 2 \mathrm{~min}$ at $55^{\circ} \mathrm{C}$, and $2 \mathrm{~min}$ at $72^{\circ} \mathrm{C}$ followed by a final extension of $7 \mathrm{~min}$ at $72^{\circ} \mathrm{C}$ then immediate storage at $4^{\circ} \mathrm{C}$. Each RT-PCR included control groups: one tube contained only GFP 1 and GFP 2 primers, and another tube contained only embryos or fish total RNA mixtures. The PCR amplification products $(5 \mu \mathrm{l}$ of $20 \mu \mathrm{l}$ ) were analyzed on $1.5 \%$ agarose gel and transferred to nylon membranes (BioRad). The membranes were probed with $\left[{ }^{32} \mathrm{P}\right]$ dCTP-radiolabeled GFP cDNA fragments. The hybridization procedure was the same as that used for isolation and characterization of tilapia IGFs genes described above. 


\section{Tilapia IGF-II promoter region}

-5477 TGGTAAGCTTGCGACCGCCCTAGGACTAGTCTCGAGGCTAGCCCATGGGG - 5427 CGCCGGGCCCGGATCTGTGTTTGGTATATTTGATTTAAACAGGGCTACAC -5377 AGATCCTGCCTACAGACAGAGGAGGAGAATGATTGGTGACATTGCCTTCA -5327 GATACAGATAGTGAGATGGGCCTTTTCCTAAATACTGCGCACACAACCAT -5277 AAGAAATAGACATAAAAGTGAAATGTAATAATTGTGTGCATATGTTTGTC - 5227 CTCAGTGGGCAGTCGATCCCCAGACTGGAATACACAGAGGAGGAGATCGG - 5177 CACATGGTAAGGGGCTCTTTCACGTTACTTTCCAATATTGATAATATATG -5127 ACATGAAAAGTTAAGTCTGAAGTAGCAGTGAGAATAAAATCATAATTTAC -5077 AATGAACACAAAATGTTTTTATCTATTAAAATACGTTTCATTGTTATTTT - 5027 GTTTTACTGTGAACACATTGTGCTCAACCCAGCAACCAATGAGTCATTTG - 4977 CATATGAATGGTCTTTTATGGATGCTTTGGTAAATTTAACTTCAGATGGA -4927 GGGTGTCACTAGAATAAACTCGAGGTGACAGCTCGAGCTTGTCTGAATGA - 4877 AAAACATATCCATAGCCTGAGAACAAAGTGTTGTTTGCAATTCAATAGAT -4827 GTTTATCATTTTACTTGAACAGTTTAGGACAAAAAAAAAGGACACTAATG -4777 AATGAATTTAGTCACCAGACCAAGTAGAAAAATTATAGCAAAGTGCTTTT -4727 TCATAAGATTTATACGATACAAGAAAAACACAGCATAATAAATAGTTAAA - 4677 CATTGCAGGATAAATCCAATTTAAACACTGTTAATTAGGAGGCGCATAAC -4627 ACTAACCATAACTCTAAAACTACACTGCAATTTTACTTATTTCCAAAGTT -4577 TTTCCAAGATTTTGATTTTAATAAATGAAACCTCAATTTTTATGTAATTA -4527 AATACTGATTTAGGCGAGAAGTATATTCAACCCTGAGGGACTTGTACACC -4477 ACCCATGCCTGCAGTGAATACCTTGAGGCTTTTCGTCTCCTAGAAAGGCA - 4427 TTGTGGGTACAGCCCAGACAACATTCCCCAGCTGGAAGATGTGTCACGCT -4377 TCCTCAAAGGTAAAAACGGGATAAGACNAAATGAAAAAAGAAAAGATACC -4327 TAAATACAGACGCTTAGCAAATGTAGACTCCACCTATCAGGGTTTGGATT - 4277 CTCTCTCTCTCTCTCTCTCTCTCTCTCTCTTGCTTACTGTCGCTTCACCA - 4227 CCATCCCCCTGAACACACACGCCAGAGCGCCACAGGATTTCAGCIGCGTC - 4177 CAGTGGCGGGGCCTGCTCTCAGCCAGAGATTTTCTGGCCAGTTTGGCATT - 4127 CCGAGTGTTCCAGTGCACCCAGTACATCCGACATGCTTCCTCCCCCATGC - 4077 ACTCCCCAGAACCGTGAGTACTACTGTGACTCTTTTGGCTTTGTGCTTCA - 4027 ACTAATTATAAAGTATACAATCAGAAATAGCTCCATAAAAACAAAAGCAA - 3977 GTGAAATTACACATAGCATCTGCTAATAGCAACAACAATTCATATTAAAA -3927 AGCTGCTGTATGCAAAAGCTGTTGTGTTTATGTAATTATTTTAAGATTCA -3877 ATATGTTTTTCTTTAGAGAACAGGCTTGCTTTCATTCTGTTACTGTTATG - 3827 TAATCAGATTGAATTTCCAGTTTGIGATCATAAAGTCTGCATCCAATCAA - 3777 ACTGAACTGTGTGGTGTTTTTCATTTAAGATCAAACATTGTCGTGAATTA - 3727 ATATAACTGTTGCTTTCTCTTCAGTGACTGCGTCCATGAATTACTGGGCC - 3677 ACGTACCCATGCTGGCTGATCGCACTTTTGCCCAGTTTTCACAGGTTAGT -3627 GCTGAAACGATTAGCAGCCTTACAGATCATTCAGTTCTTTTGTGCTATTT - 3577 AGCAAGAATTGATCTATTATTTTCCACAGAACCTTGGTTTGGCTTCACTG - 3527 GGGGCTTCGGATGAAGATATTGAGAAACTGTCCACAGTAAGACTTTTGTC - 3477 TTCGAACACAAACAACACATGCAAACTGTATAAAAATTACTGCGGTGAAG - 3427 TITGGGGTTGAACCTCATGTTGCCAGCCCATCCCCCCAACAGAGACACAC - 3377 ACACACACAAACACACACACGCTCCCACGCTTCTTAGCCTGGGCTTCAAG -3327 CACGAACTGAGATACATATCCCATATAGTAAACAATAGAATTAACTATCG - 3277 CTAAAATATCTTTCAAAATACATTACTTTGGACAGCCTTGTCTAAAATCT - 3227 AACATGTAGCTAATGCACTGATTGTCCATACTTCTTCTCAGTCACCTCCT - 3177 TTCTGTTTTTCCATCAGCTGTACTGGTTCACGGTCGAGTATGGCTTATGT - 3127 AAACAAAATGGTGAGGTGAGGGCTTATGGAGCTGGGCTGCTTTCCTCTTA - 3077 TGGTGAACTTGTGGTAGGTTCACACGTTTTTTTTTTTTTCTTTAATGCAG -3027 GACACACAGACAGCTGTGAGCTAATTCTCCATTTTTTTAAACTTCCAGCA - 2977 CTCTCTGTCTGATGAACCAGAGACAAGAGAGTTTGATCCAGAGGCTGCAG
-2927 CAGTGCAGCCCTATCAAGACCAGACGTACCAGCCTGTTTACTTTATTTCT - 2877 GAGAGTTTTTCAGATGCCAAGGAGAAATTCAGGTACTGCTCTTTATCGTA - 2827 CCAGACATACACCTACATAAGAACATACAGAACTGATAAAAAAAATGTGT - 2757 AAAAAACAACAACGAAAAACAAAAAAGAGAGGGGTTATGTGAGGACGAGG - 2727 TCAGAGAACAGCCAGCCAACCCCGGAGGCCACAAACTATTGTAGGTCAGC - 2677 CATAGCAGCCAGAAGACAGCTGTTCCTAATGTAGTCTTCCTTACCAAGGC -2627 AAAACTCTGGAGTTTTATTTGGCAAACAGATCAAATGCTGCCCTGCCAAA - 2577 CAAGTATCTTAAGTGAGTGTGTTCACAATATTCAGCCTCTAGTAGAATGC -2527 AGCACATGACATCTCGGACACACTGGATGAGGAAATACCCGCACTGGAAT -2477 GTTGAAAGAGCACAGAGAACATTGTGAGCATCATACATAGGAGTATATCT -2427 CTATGTTGTGGAATCCACAGTCTCAATAATTTGCATGCATGTGCAACATG - 2377 GCAAATTATAACAACAAGGACAATTTGCAGGCATGGTTGCTTTAGTCCAT -2327 ACTTTCAGTTGGAGCATAAAGACAGCCCCATTTGAGATCTTTAAGTTTCT -2277 GACTTCTTTACATCTTTACAATTTTGACCAGGGCTTATGTAGCTGCCATC -2227 AAGCGTCCCTTCTCAGTCAGATTTGATCCATATACCAGCAGTGTTGAAGT -2177 ATTGGACAACCCAGTGAAGATCCAAGGAGGCCTGGAAGGTGTGAAGGATG -2127 AGCTTAAAGTGCTGACAGACGCCCTAAGTGTGCTATCGTGATGATGCGCT -2077 GTCTTTCACCATCCGCCTGTTGTTTGCTTTTCTCTCCGCTGAGTCCACGC -2027 TGTCGAAGATCGCCAATGTCTTCATATTTCTGTGCCGTACCTGCTGTATG - 1977 AATCTGAGTTTTGCTTGTTGTGGTTGGCTGGTTGGCCAGCAAGGTTGCAA - 1927 CCATTAAAACCTCAAAACTCAGCGCTGACAAAGTATCCAAAGATCTTAAA - 1877 TGCTTGCATTTGTGAAATGATGGGGTTTTACTGACTGGACCATTCATGCT - 1827 TTTAAAGTTTGTTGTTIGAGAAATGTGTCAAATCTAGAGTCACATCAAAG -1777 GGAACTCTGATAATGAAGAATAAAAGGAGGTATATAAGAATGGTATAGAA -1727 TTTGAAACTAAAGAATTATAATGGTGAATATTTGGAACATTTATTTTATT - 1677 TAGAAAAAAATCTGTAACTGCTCTGTCAAAAGCTTTATTTTCCAAATATG - 1627 AGAATTTAGCTTTTGAGTAATTAAATCCATAGCTTTCATATGCTGTTCTT - 1577 GTCTTGCATTGTGTATTTTATGCTGGTTTCGTCTTGCAGTGTAAATGCAT - 1527 AATAAAAAAAAAGGGGGGGGAAGAAAACATAGTTCCTATGTAATAAACT - 1477 ATTGACTACAAACTATCAGATAATAAAGAACTGCAAATTAACATTTCACT - 1427 ATCGTTTCTGTGATTTATCAAGTTTTTATTCCTACAGTTAAACTAAAAAT - 1377 ATAAATAATAGCATTATATTTGATAGGTTTTGGCTCTTATCGCTGATGGG - 1327 AAAACCTAGAAATACTTTCACATGAATTATTAGTTAACGACACCTGGCTG - 1277 AGTCTTGCTTTACATTTGTCTATCGCAAGAGGGAGCTGTCTAGCIGTTTT - 1227 CGCCTGCCTCGTCATAAAATCACAGCATATTTATTGAATTTTTTTTTTGAG -1177 AGAATAAATCTTAAGGTTCTCTTCCTGTCACCAATCTCTGTTTTGAGTTA - 1127 AAAACAAGCTAAAGCTCACAAACAACCTCAAGATATTTTAATGACACTAA - 1077 ATGCACTATAGAAACGCTATTTAATGTGCTGTATTGAAAATAAATAAATA - 1027 AATAAATTAAAAATCAGCCGTTTTTGAAACTGTTATTCTGCATAATCATC -977 GCATAAGAGAGAAAAGTTAGCTGTGAAAGAGAACACGAGTTTGGTGGGA -927 CACGCTTCCTTCTGTTCAGGTAAGAAGATGCGATCATATCCAGGATTCAA -877 CATTCCAGGACAAAAGCTGGAAAGCCGAAAGCTGGAGGACAAACAAACGG -827 AGGTACCGTAACCAGACCAGCAGGTGTCAGTATGAGTCTGAAGACACGTG - 777 CAGATCTTTAACTTCACCAGAGCACACACCGAAATAAGGGGGCCCTCGAG -727 TTTCATAAAGCATAACGTGAATGTGCGTGTTTATATGTTAAATTCAGATT -677 TTCAAAGTATGGATCACTCTTTGTATACTCGGACGGAACCTATTCCATAT -627 CTGCAATGAAGTAGTGCTGCTGGACTGTACGATGCATATTTGTCATAATG -577 TGCATACTAATGCATTAGTAAAGCTTTTAAAAAAATCTCCACATTTGTCT -527 CAATGCTGACTCTCCATCATATGACCATCCATAATATCTGTGGCTTGAGA - 477 CATGCCTGCATCTACTTTCCCACPTGGTGTCCCGCTGCATCCGC TTTCCA P3 Primer

-427 CTGCATCAACCCCGTTTACTATCTCCCCTTCACTGTCAGGCACCTTTGAC P4 Primer

FIG. 4. Nucleotide sequence of promoter region of tilapia $I G F-I I$ gene. Numbered arrows under sequence indicate positions for CAT assay of PCR-constructed primer. Regions of 5'RACE termini are marked by arrows. Exon sequences and 5' flanking sequences are shown in uppercase letters; intron sequences are shown in lowercase letters. Translation initiation codon is underlined and marked*. 


\begin{tabular}{|c|c|}
\hline-377 & CCCAGTGCCTGCATCTACACAGTCTGAGGAAAGCCGCAAACCTTGGCCAC \\
\hline \multirow[t]{2}{*}{-327} & 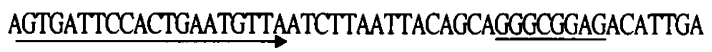 \\
\hline & P5 Primer \\
\hline \multirow[t]{2}{*}{-277} & CATTTTTCTTGGAGTCGAAGGAATTACCCCTATTCTTGTTCAGTCTGCGT \\
\hline & P6 Primer \\
\hline \multirow[t]{2}{*}{-227} & 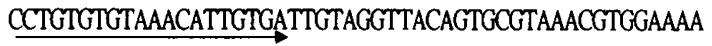 \\
\hline & P7 Prin \\
\hline \multirow[t]{2}{*}{-177} & ГTTTGTGACTCTCACCCTCTTATTCTCCC \\
\hline & P8 Pri \\
\hline \multirow[t]{2}{*}{-127} & 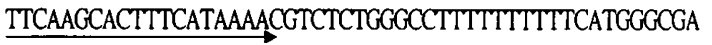 \\
\hline & P9 Primer \\
\hline \multirow[t]{2}{*}{-77} & AGAGGAGGAGCAAGGGGTGGGGTGGGTGTAAGGCGCGTCCTTTAGTATAT \\
\hline & $\stackrel{5}{\longrightarrow} \mathrm{RACl}$ \\
\hline-27 & AATACCTCTCCCTGAGAAGTTTTGCCTFTCGCCTAGTCTTTGGGACAGCT \\
\hline 24 & TCTCACTCACCATCTCTATAGTTTAACCAACTGGGAAACTAACTCACCTG \\
\hline \multirow[t]{2}{*}{74} & CAATCACACCAACCAAATAATTCCCAACATTTTGACTACTGCCATCTGAC \\
\hline & P11 Primer \\
\hline 124 & ATGGAAACCCAGCAAAGATACGGACATCACTCACTTTGCCACACCTGCCG \\
\hline 174 & GAGAACGCAGAACACCAGATGGAAGg t aaccaaagaacaagcaaat tg $t$ \\
\hline 224 & t tat actctccgggtctgccgtgcgcgt aatgaaagacgtctgacaggt $t$ \\
\hline 274 & tatagcggtgt tgtct tggt t t at aagt aggaaaaccagt tcgggt tct \\
\hline 324 & gtagatgcagtgctcgcatcagtt t tgtgcagtatgagccccggg \\
\hline
\end{tabular}

374 tt tgat t tgtatgcagcagagaaagt tcaaga tgcat aaacggcgagga

424 gaagct t tgcggcat t tgggat agaaaaagaacaag taat $t t$ tag $t c t$ tc

474 tcgcgcctggatggtgtcgtggacacggagcaaacagctgat $t \mathrm{t} t \mathrm{t}$ tacc

524 ggcagatagggggcggcaggt t tgagggtcag tgagctcat tccgggtg

574 agcaaagggaaaat at atgctgagt t tgg tgt $t t t c g g c t a g t$ taactat

624 cgagcagccggcet tgcaact tcaggatggt tg tgtaagagtggaaagct

674 ggtgatactggcgact tgtgttt tt tcctccagaataagcact tcttca

724 ggtgcgacagacatgacagcagctgat aatagcgggcggggaagg tgaag

774 agcgggtctgcacat tgtgact tgat tgagatgat t tct tt tctgaa

824 t t tctact tgtcgaacat t gagcacg tacaccg tacacaccgggagcc

874 tgtgatgaagactgtaccctct cgtctgaaaaaaaaaaaaaactctg

924 gctgat tt tgat taaaaaatggtat t taactgtcat taactgt tat $t$ t

974 gt taacgat t tctgtatgccacaact t tctgcatatcatggctacat t tg

1024 gtgaccccatgct t cat accgcagGTCAAGAAGATGTCTTCCACGAATC

1074 CCGCGCTGCTCTTTGCACTGGCCCTGACGCTCTACCTAATGGAAATGGCC

1124 TCCGCGGAAACCCTTTTTGGGGGAAAACTGGTGGATGCGCTGCAATTTGT

1174 CTGTGAAGACAGAAGCTTTATTTCAg taag $\mathrm{t} t \mathrm{t}$ caaagca $\mathrm{t}$ acnag $\mathrm{t} t$

1224 tcccaatggctgcgtgat tgctcatt tgcctgt tgaatctctctgt tgt

1274 gcct tgcacacatctgt t tggagcaaaag tgggaagt tacccactacna

1324 a tact tcgt tactgtactccagtatag $t \mathrm{t} t$ tcagt tagaat $t \mathrm{t} t \mathrm{tgccc}$

1374 ctacattttaaacagatatctgtact tetactcc

FIG. 4. Continued

\section{RESULTS}

\section{$R T-P C R$ cloning and characterization of tilapia IGF-I $c D N A$}

To isolate the $I G F-I$ coding region from tilapia as quickly as possible, our strategy included injecting seabream GH and comparing multiple piscine $I G F-I$ sequences (salmon, rainbow trout, seabream, hagfish, and catfish); after this, two primers were designed. For simplicity, an EcoRI restriction enzyme site was designed to clone the IGF-I RT-PCR product. A total of $20 \mathrm{E}$. coli clones were selected and sequenced, and three clones were identified as tilapia $I G F-I$ cDNA sequences. The nucleotide sequence and predicted amino acid sequences of tilapia $I G F-I$ are described in Figure 1. The tilapia IGF-I cDNA insert contains $549 \mathrm{nt}$, which encode 183 amino acid residues. Herein, we identify a tilapia IGF-I cDNA sequence containing a signal peptide (132 nt; 44 amino acids), B domain (87 nt; 29 amino acids), $C$ domain ( $27 \mathrm{nt} ; 9$ amino acids), A domain (66 nt; 22 amino acids), D domain (24 nt; 8 amino acids), and $\mathrm{E}$ domain (210 nt; 70 amino acids). The tilapia $I G F-I$ nucleotide and amino acid sequences were compared with those of rainbow trout $I G F-I$ and possessed $86.6 \%$ and $84.9 \%$ homology, respectively. The tilapia $I G F-I$ nucleotide and amino acid sequences were compared with those of salmon IGF-I and possessed $86.8 \%$ and $85.4 \%$ homology, respectively. Comparison of the amino acid sequences for fish in Figure 2 and Table 2 shows high evolutionary conservation. The homology between IGF-Is indicates that amino acid substitutions are relatively few, and the IGF-I mature peptide sequence is highly conserved (Fig. 2). The mature insulin and IGF peptides are highly conserved among vertebrate species; it can be inferred that IGF-I-like molecules were found in species with origins from 550 million years ago (LeRoith $e t$ al., 1993), which is near the beginning of the Cambrian Era between the Paleozoic and Proterozoic.

\section{Characterization of tilapia IGF-I gene structure}

In tilapia IGF-I, the first exon encodes a partial signal peptide and is highly conserved in the $5^{\prime}$ untranslated region. The B, C, A, and D domains of the mature peptide are encoded by exons 2 and 3. The first $E$ domain of 40 amino acids is encoded by exon 3 . The second $E$ domain of 11 amino acids is encoded by mini-exon 4 . The last $E$ domain and part of the $3^{\prime}$ untranslated region are encoded by exon 5 .

The partial nucleotide sequence of the Oreochromis mossambicus IGF-I gene is shown in Figure 3. The gene contains five exons, and the exon structure is like that of chum salmon. All five exons and part of the introns were sequenced, and the genomic DNA sequence was compared with the Oreochromis mossambicus IGF-I cDNA sequence. From exon 2 to exon 3, the junction of the intron could not be amplified by PCR. So, unlike chum salmon, it could not be determined whether the tilapia sequence of exon 2 to exon 3 is divided into about a 10 $\mathrm{kb}$ intron. We surmise that the separated intron may have the same structure and nucleotide length as that in the chum salmon gene. In tilapia, exon 1 to exon 2 is about $1.8 \mathrm{~kb}$, and exons 3 to 5 are about $3.1 \mathrm{~kb}$. Exon 1 is separated from exon 2 by a $1.2-\mathrm{kb}$ intron. Exon 3 is separated from exon 4 by a 173-bp intron, a mini-intron. Exon 4 is separated from exon 5 by a 2.5 $\mathrm{kb}$ intron. In the chicken, human, rat, and salmon (Kajimoto and Rotwein, 1990; Kavsan et al., 1993), there is a TATA-like consensus sequence of about $300 \mathrm{bp}$ upstream of the first methionine, but no CCAAT-like or GAGA sequence was found. 
1 at tgaacaatatnttatnaccntaatgaatgatcct tctt t tccett tt

51 ct tctatt t cgcccgcacgccacaat agGAAGTTCAGAAGAAGCAACAT

101 GTGACCGTGAAGTATTCCAAATACGAGGTGTGGCAGAGGAAGGCGGCCCA

151 GCGGCTCCGGAGGGGTGTCCCCGCCATTCTGAGGGCCAGAAAGTATAAGA

201 GGCACGCGGAGAAGATTAAAGCCAAGGAGCAGGCTATCTTCCACAGGCCC

251 CTGATCAGCCTTCCTAGCAAGCTGCCTCCCGTGTTGCTCACCACGGACAA \#

301 CTTTGTCAGTCACAAATGAGCCOGCTGCCAGCCCTTTGCACAGACAAGAG

351 TTTTGAGGGTGAAAAAAAGACTAGGGGATTATAGCTTTGGTCTTCTGACG

401 TCATTTCTGTGGCAGTCCTCTTTGACCTCCCCTGCCCTGTCCGAGCTCAC

451 CAATCCCTCCCCCTGCACATATCCACTACGTCTTGAACCCCTGGCCCTTT

501 TCTAATGACCCNNTTAAACCCGAACTCCCCCCTCCCCACCAACCCACCCT

551 CCTCTGGCACACAGACATGCCTTCACATTCTTCCIGTCTGAACTCTTTCT

601 CTCCCACTCTCTTTCAGTCACTGATACAAAAGGCACAAACACAAAACGTC

651 GAACAAAAAGTTAACAATTTGGCTGAATGCGGTTCAGGTGGATCCTTAAG

701 CAAAAGACAAAAAGAGAAGGGAAAAAGAAGATGAAAGAGATCTGTCGTTT

751 GCAAGTGTCAAGAGGACACCTAGCGGAATGTTTTTTGTCCTTGTGGAAGA

801 CAACTGAAAGTGAAGAGCTGCTTGCATGAAAGAATCCATTCCACCTCATT

851 TTCCTGAGGCAAAAGAAAATCTCTGTTAGTTCTTTAGTTTGCACCTCTAC

901 CTGTAATGGGACTTCCACACTGTAAGGAATTATTTTGTAAAATTAGATTC

951 CTGTTCCAGCACCTTTTGATCACAAACAAAAAGCAGAAAAGAGTCTGCAA

1001 AATTGCACATTGCCACCGSATTACGTCTTTGTAAGAAAAAAATGGGCACTA

1051 TTTTTTATGAACAATGAACGTGTAGCTTAAAAAAATGTCATGGTGCTAG

1101 CTTTGGGAATGGACTCAAAGAAGAGGTGGAAAAGCACGTTTTTTTTTCTT

1151 TGAATTAATAATTAAAGCTTTCCGTTTTAAGGAAAGTGTGACTTTTTAAA

1201 AAAAGGAAAATTTTGGATATGGGGGAGCTCAGCCGGGCACCAGGCCCGGC

1251 AGCGNCAGGGGGGGGGGNCACCGGGGGAAAACACGGGCCGCGATGGCACC

1301 TAGGCTCATGGTGGGAGCTAGCGGCTGCTATTTACTAGCTTGCCAGCATA

1351 AGCAGCAAGGGGAGGCCCGAGGCCTAGTCCCTGCTCCTCCTGCCCCTCTG

1401 AGGCTGCTGGACACATGGAGCACTATGGGGACACATACGGGACACCATGG

1451 ACCACCTGGATTGGGACAGTACTATAGTTCGGGGACAGTACTTCCTGTTT

1501 GCCATGGCTTTGCGGACTGTTCTGGCAGGAAGTAACATGGCATGGACTAA

1551 GAACGAGTGGGATAATGATGATTATATTTTATTTTTTGTCTTTTTTCATA

1601 TCAATGTTTCAATGAAAAAAAAAGGAAAACCCTGTCAGTTTCTGGTACCG

1651 TGACATTCCTGTTTTTCCAAGTTAGGCTTTTTTTTATTGTTATGATGTTA

1701 TTTTACAGTTATAAAGAAAGGGAAAAAACAGCAATAATGTCAACTAACAT

1751 TTTATTTTTATTGTATCTCAGTAGTATACACATGCTTGCGCGCGAACACA

1801 CATACGTGAATATATATATATATATGTATATATATATATATATACACATG
1851 TACACATGTATATATATATATATATATATATATATATATATATACACATG

1901 TACACATGTATATATATATATACACATATATATGTGCGCATATATATAGA

1951 TATATATATAGACACTCATATATATATATATATATATGTGTGTGTGTGTG

2001 TATATATATATATACACATATATATGTGCGCATATATATAGATATATATA

2051 TAGACATCCCCCATATATATATATATATGTATGTATGTGTGTATATATAT

2101 ATATATACATATATATGTGTGCATATATATAGATATATATATAGACATTC

2151 ATATATATATATATATATATATATATAGATATATAGATAGATATATAGAT

2201 ATACTATTAGTTTCCAGGGACATTGTGTTATTTTGATACTAGTCTGAGCT

2251 GTACCTTGCGTAATGAGCCGCCAAGCTTTTGTACCTTGCGTAATGAGCCG

2301 CCAAGCTTTTTTGTTCGTTTGTTGAAATACAAATAAGGGCACTGTATAAA

2351 GGCATTATTTATTTTGTTATAAAATATATTTGAAAAATTGGTCCAAATAA

2401 TATACGTAGCACTGATGCTCAACTGCTAGATTTATTTTGTATGGTCTCTG

2451 TTTTCCAATTGGAGTTGTAAGGCTTTTTTTTGTAGATGCTTTGTACCAAA

2501 AATGTTGTTTTTTTCCTGTTTCATTTGCCATAGTCCTTTAAATTAATATT

2551 TTAACAGCAGCATAGCCTGGATTGCTTAGGCATGTTATGTCACAAAAATA

2601 GGCACATACTCCTAATCTGTCGGTCTGCATGGATTTCCAGAAGCCTGTCA

2651 GGGTTGTCTGAGAAAATGAAAGCATCAATGAGTAACTTTTTCATTGCTGA

2701 AAAAAATGAGAAATAACTGTTCAGCATGGATATTGCCTCAAGCCCCGCTA

2751 TGTTTTTTAAGCCACTTTAGTATTGATGGCAGGGGAGGGGGAATGACGA

2801 GTCCTTCATTAAACTGTGTCTTTATAAGTGTGCATGGTGTCCTATGATCT

2851 TCTAAGGAACATCTAATGCAGGTCAGTCCCACTGATACTCTTGGTCGGGT

2901 CATGAGGCCATAAATGTCCACTCAGCTGTGGAGTTGTGGGTTTGCATTAC

2951 ACATGACCTAACCAAGTCATCCTATTCATGCCGACCTTGGTGTGATGCTA

3001 GCAAACATCAAAGGTCATTTGAAAGTCACTGTCTGTCAAAGAGAGACTGA

3051 CGATCTATCTATCTATCTATCTATCTATCTATCTATCTATCTATCTATCT

3101 ATCTATCTAAGTCTCTTTTTGGTATAGCACAGTGACTCTGTGCATCATCA

3151 GCATATCTTGAGCTTGTGCATCATCAATATGCATCTGTATTTGCATTGGG

3201 TTTGGGGTTCGGCATTCATCCCTCGGAATCTTCCACTAATGCATCCATTA

3251 TGCATTTAATGAAGGGCTATCATGCTGAAGCATTTCTGAAGCGCTCAGGA

3301 AAAAAAAATGTGCTCTCTAAGGGAGAAGTGGAATCGTTGCTGAGTTTAGG

3351 AGATAATCTTGTTGTGGAAGGTGAGCTGAGGTTGTTACCCATACCTGGCC

3401 ACAATAATATAGTTCTCTGTAACAAACCACTGAAGCCCATGTCAGAAGCA

3451 AGGTCATCCTGTGCCACATTGTCACAGTTTCCTCCTCTGTTGTGTCATGC

3501 ATCACCCCATGAAACGGTGACTCAATGGATAGTTGCCATATTGTGGTGTA

3551 GAGTCGAGAGAACACTTTGTCTTTTTTCTGTCAGAGAGATCCGGGCCCGG

3601 CGCCC

FIG. 5. Partial nucleotide sequence of last exon of tilapia $I G F-I I$ gene. There are putative polyadenylation signals at positions 1153-1158, 1160-1165, and 2541-2546, which are underlined. \# = stop codon. PreproIGF-II stop codon (TGA) is underlined and occurs at position 317-319. A poly(AT) stretch is present between positions 1801 and 2201. Exon sequences and $3^{\prime}$ flanking sequences are shown in uppercase letters; intronic sequences are shown in lowercase letters.

Examination of the $5^{\prime}$ flanking region of tilapia showed several potential transcriptional factor-binding sequences, a TATA-like consensus sequence of about $300 \mathrm{bp}$ upstream of the first methionine, one possible HNF-5-binding sequence, one possible HNF-1-binding sequence, and one possible AP-1-binding sequence.

Characterization of tilapia $5^{\prime}$ and $3^{\prime}$ flanking regions of IGF-II gene

Using data published before (Chen et al., 1997), we continued to sequence the subclone of $I G F-I I$ genomic DNA. The entire DNA sequences are shown in Figures 4 and 5. The partial nucleotide sequence of the Oreochromis mossambicus IGF-II gene is shown in Figure 4, which depicts the sequence of about $5.7 \mathrm{~kb} 5^{\prime}$ upstream of the first methionine sequence containing the tilapia $I G F-I I$ promoter, as determined by the research reported in this paper. As in the human IGF-II $\mathrm{P} 4$ promoter sequence (Hyun et al., 1993), there are a TATA-like sequence, several $\mathrm{G}+\mathrm{C}$-rich regions, three possible Spl-binding sequences, one AP-1-binding sequence, and a C/EBP-binding sequence. In tilapia, there is an undefined TATA-like sequence of $25 \mathrm{bp}$ in front of the 5'RACE end. There is one possible Sp1-binding sequence. Between $-5477 \mathrm{bp}$ and $-4477 \mathrm{bp}$, there are one possible DBP-binding sequence, one possible GHF-1-binding sequence, one possible AR-binding sequence, and one possible 
A

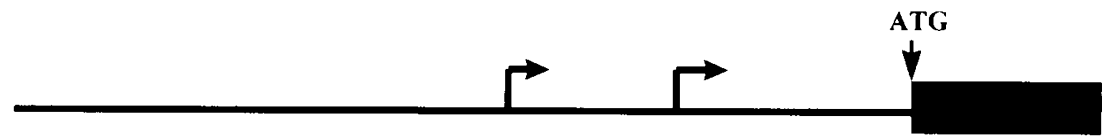

Plasmid

Relative Promoter Activity (\% MAX)

pCAT basic (promoterless)

$1.0 \pm 0$

IGF-I P2 $\rightarrow$ P7 (657 bp)

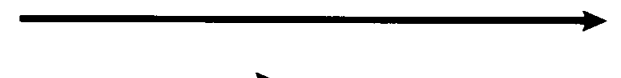

$46.4 \pm 7.8$

IGF-I P3 $\rightarrow$ P4 (308 bp)

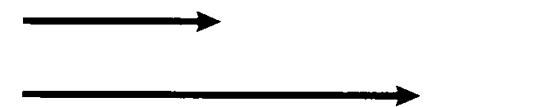

$32.2 \pm 4.5$

IGF-I P3 $\rightarrow$ P6 (408 bp)

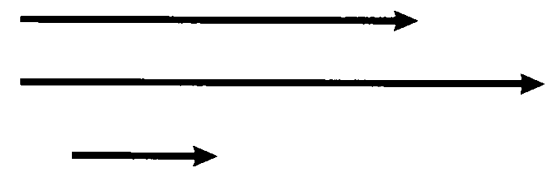

$1.0 \pm 0$

IGF-I P3 $\rightarrow$ P7 (510 bp)

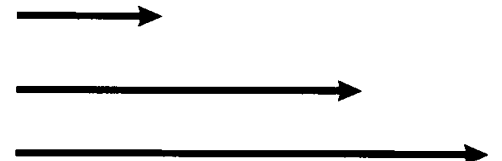

$27.8 \pm 4.4$

IGF-I P5 $\rightarrow$ P4 (132 bp)

$13.6 \pm 2.2$

IGF-I P5 $\rightarrow$ P6 (232 bp)

$1.3 \pm 0.1$

IGF-I P5 $\rightarrow$ P7 (333 bp)

$28.2 \pm 5.0$

B

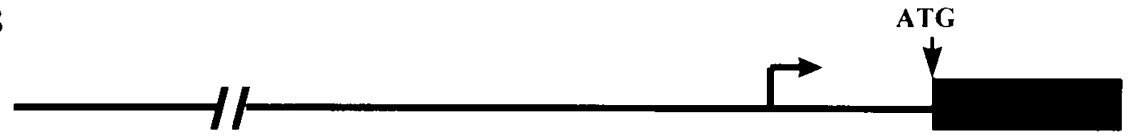

Plasmid

pCAT basic (promoterless)

IGF-II P3 $\rightarrow$ Pl1 (600 bp)

IGF-II P4 $\rightarrow$ P1l (550 bp)

IGF-II P5 $\rightarrow$ P11 (450 bp)

IGF-II P6 $\rightarrow$ P11 (400 bp)

IGF-II P7 $\rightarrow$ P11 (350 bp)

IGF-Il P9 $\rightarrow$ Pll (250 bp)

IGF-II P7 $\leftarrow$ P11 (350 bp)

IGF-II P8 $\leftarrow$ P11 (300 bp)
Relative Promoter Activity (\% MAX)

$1.0 \pm 0$
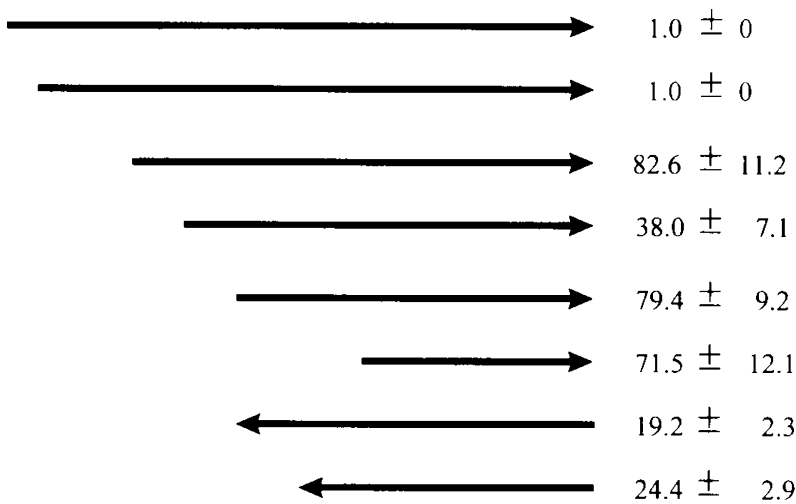

FIG. 6. Identification of promoter activity in $5^{\prime}$ flanking region of tilapia $I G F-I$ gene (A) and $I G F-I I$ gene (B). The IGF-CAT fusion plasmids containing fragments of 5' flanking region were transfected into human lung large cell carcinoma, and CAT activity was measured $48 \mathrm{~h}$ later as described previously (Tsai et al., 1996). All transfections were performed in triplicate. Values (mean $\pm \mathrm{SEM}$ ) represent CAT activity relative to that in cells transfected with promoterless plasmid pCAT-basic vector, defined as 1.0 .

HNF-5-binding sequence. Although we did not characterize this region, we surmise that it contains another promoter. In the $3^{\prime}$ flanking regions of the tilapia $I G F-I I$ gene, we found that the last exon contains an $\mathrm{A}+\mathrm{T}$-rich sequence, which proved to include the complete sequence of a $3.6-\mathrm{kb}$ genomic region downstream of the $5^{\prime}$ boundary of the last coding exon (Fig. 5). In the rat, a $3^{\prime}$ terminal exon can be found, and two polyadenylation signals (5'-AATAAA- $3^{\prime}$ ) can be distinguished (de Pagter-Holthuizen $e t$ al., 1988), but in the tilapia $3^{\prime}$ last coding exon sequence, we could not find a legitimate polyadenylation signal; we found only three less common variants of the AATTAA signal.

\section{Determination of tilapia IGFs 5 'cDNA terminus}

To ascertain the tilapia IGFs $5^{\prime} \mathrm{cDNA}$ terminus, the 5'RACE method was applied. The results identified two $5^{\prime} \mathrm{cDNA}$ ends in the tilapia $I G F-I$ gene and one in the tilapia $I G F-I I$ gene. The $5^{\prime}$ cDNA ends of the tilapia $I G F-I$ gene compared with the 
salmon $I G F-I$ gene show a different location for the transcription start site. The first $5^{\prime} \mathrm{cDNA}$ end is the same as the salmon 5'UTR, which is 450 to $550 \mathrm{nt}$ long. The second 5' cDNA end is the same as in the salmon 5'UTR, which is 200 to $250 \mathrm{nt}$ long (Koval et al., 1994). In tilapia $I G F-I I$, the $5^{\prime}$ cDNA end is different from the human $\mathrm{P} 4$ promoter transcription start site. In humans, there are two different transcription start sites (Hyun et al., 1993), but in tilapia, we found only one $5^{\prime}$ cDNA end. The data are shown in Figures 3 and 4.

\section{Demonstration of promoter activity in tilapia IGFs gene}

To determine which regions of the tilapia $I G F s$ promoter are involved in its regulation, we constructed sequential $5^{\prime}$ deletions of the assumed promoter region, including the flanking transcription start sites described above (Figs. 3, 4, and 6), ligated with the CAT coding sequence. The constructs were then transfected into human lung large cell carcinoma cells in triplicate, and, after transient transfection expression, CAT activity was analyzed (Fig. 6). The fragment of IGF-I P2 $\rightarrow$ P7 $(46.4 \pm 7.8)$ contained enzymatic activity with a maximum value comparable to that of the other $I G F-I$ promoter-region constructs and the promoterless plasmid, pCAT-basic. Deletion of the fragment from IGF-I P2 $\rightarrow$ P7 to IGF-I P5 $\rightarrow$ P7 decreased the CAT activity. In contrast, minimal CAT activity was generated with the fragments IGF-I P3 $\rightarrow$ P6 and IGF-I P5 $\rightarrow$ P6. Comparison of the activities of fragments IGF-I P3 $\rightarrow$ P4 (32.2 \pm 4.5$),$ IGF-IP3 $\rightarrow$ P6 $(1.0 \pm 0)$, IGF-I P3 $\rightarrow$ P7 $(27.8 \pm 4.4)$, and IGF-I P5 $\rightarrow$ P4 (13.6 \pm 2.2$)$, IGF-I P5 $\rightarrow$ P6 $(1.3 \pm 0.1)$, IGF-I P5 $\rightarrow$ P7 $(28.2 \pm 5.0)$ showed that the se-

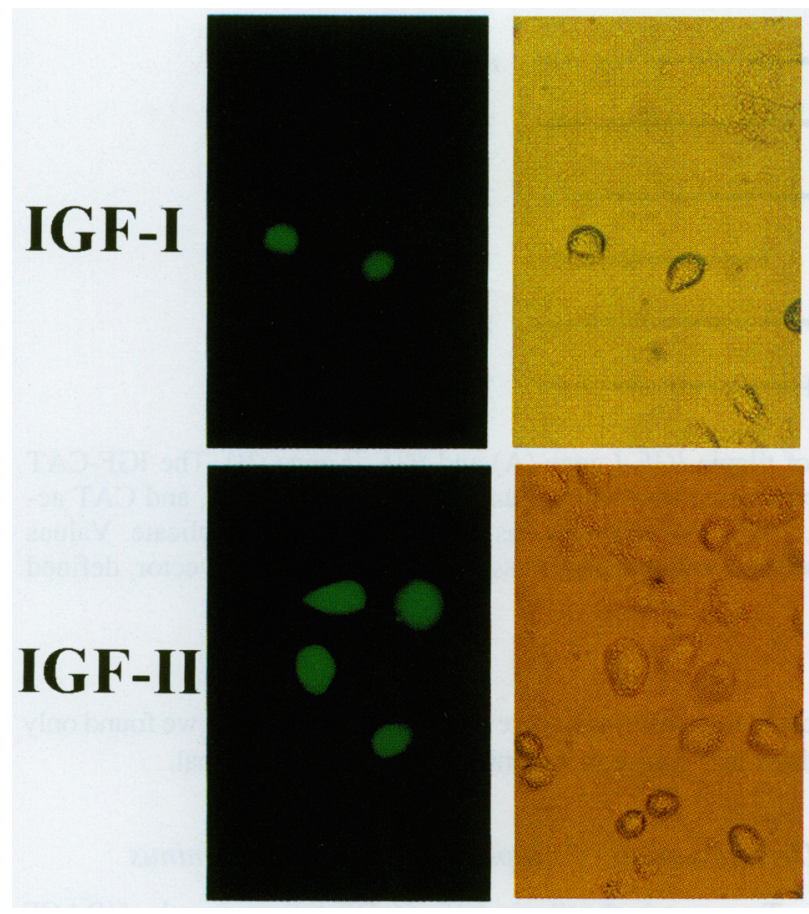

FIG. 7. Human lung large-cell carcinoma cells transiently transfected with $I G F$ promoter ligated to pEGFP-1 vector and expressing GFP. quence from P4 to P6 contains a positive regulatory element. Surprisingly, the fragment narrows to a 184-bp length (IGF-I P5 $\rightarrow$ P4); the CAT activity represents only basal transcription in this fragment, although the fragment contains all possible transcription factor-binding sequences (Figs. 3 and 6A). In the rat, the minimal exon 2 promoter is contained within the $73 \mathrm{bp}$ upstream and 44 bp downstream of the transcription start site cluster. These minimal promoters contain specific elements for basal transcription (Wang et al., 1997). However, our data show that the region downstream of the transcription start site and the sequence of about $120 \mathrm{bp}$ from P6 to P7 may contain a negative regulatory element, which gives rise to decreased CAT activity.

Figure $6 \mathrm{~B}$ reveals that the fragment of IGF-II P5 $\rightarrow$ P11 $(82.6 \pm 11.2)$ has enzymatic activity with a maximum value comparable to that of the other $I G F-I I$ promoter region constructs and the promoterless plasmid pCAT-basic. Deletion of the fragment from IGF-II P5 $\rightarrow$ P11 to IGF-II P6 $\rightarrow$ P1 1 rapidly decreased CAT activity, and deletion of the fragment from IGFII P6 $\rightarrow$ P1 $1(38.0 \pm 7.1)$ to IGF-II P7 $\rightarrow$ P1 1 (79.4 \pm 9.2$)$ and IGF-II P9 $\rightarrow$ P1 $1(71.5 \pm 12.1)$ sharply increased CAT activity. Inverted orientation of the fragments (IGF-II P7 $\leftarrow$ P11

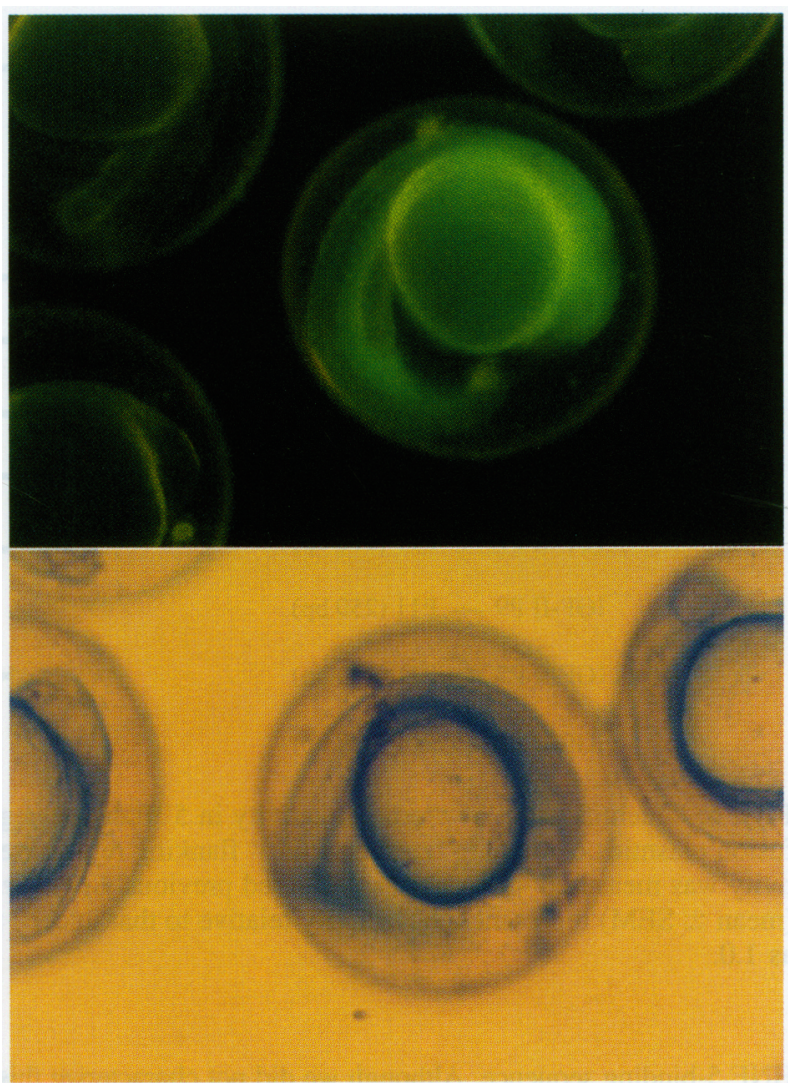

FIG. 8. Expression of $I G F-I$ promoter-GFP vector microinjected into zebrafish 2-cell-stage fertilized eggs. After $24 \mathrm{~h}$ of development in freshwater on culture dishes, GFP was first visibly expressed in whole trunk and head. Other embryo at the same stage injected with $I G F-I$ promoter-GFP vector shows no GFP. Brightfield photograph and fluorescence image (above) of same 24-h injected embryo. All photographs were taken with $45 \times$ lens on Olympus microscope IX70. 
A

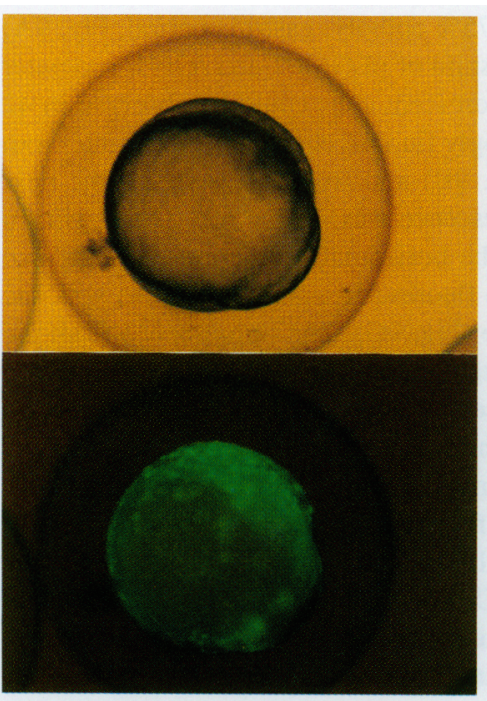

D

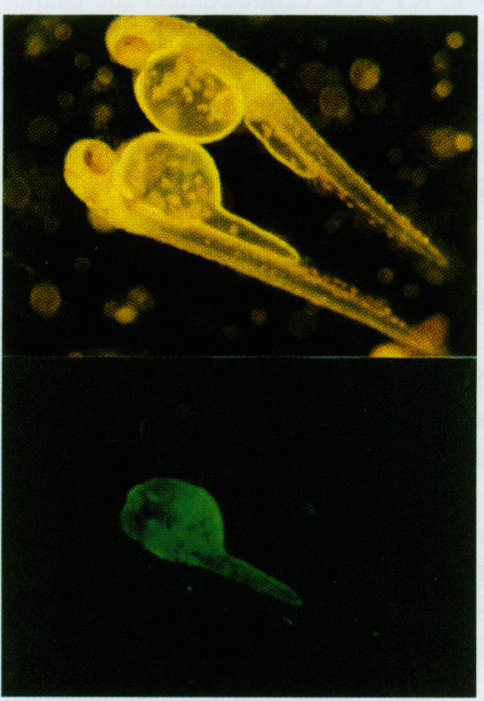

G

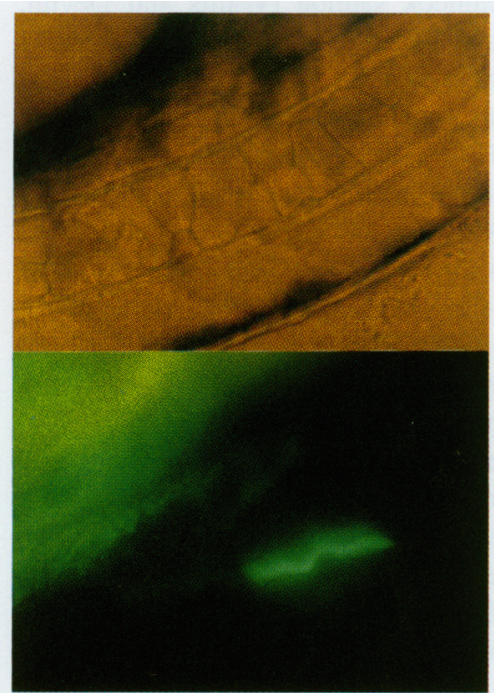

B

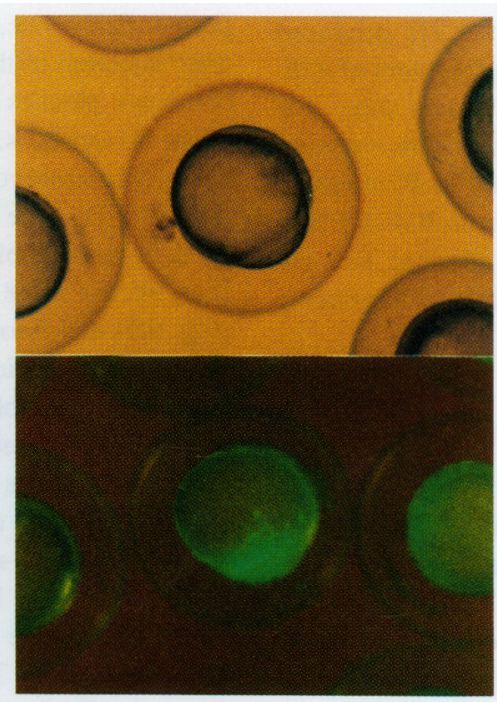

$\mathbf{E}$

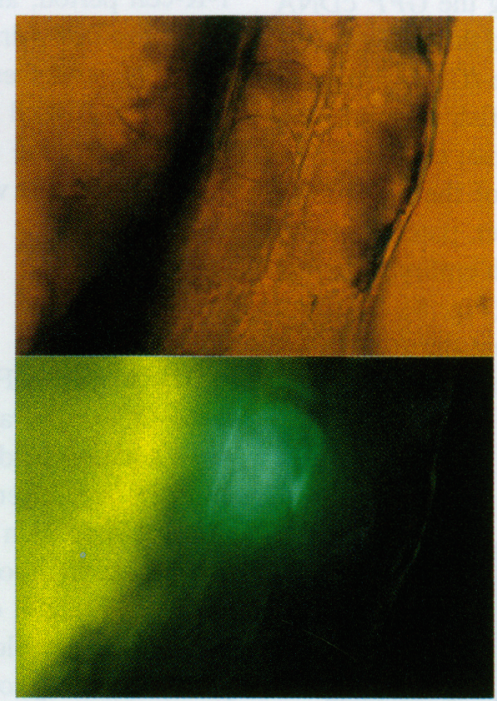

C

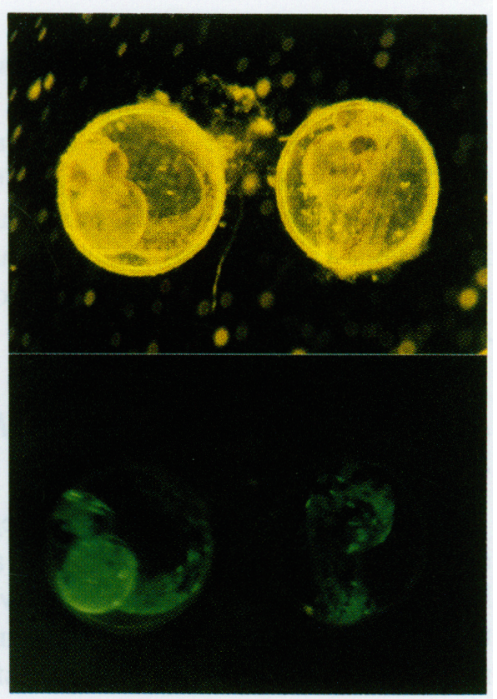

$\mathbf{F}$

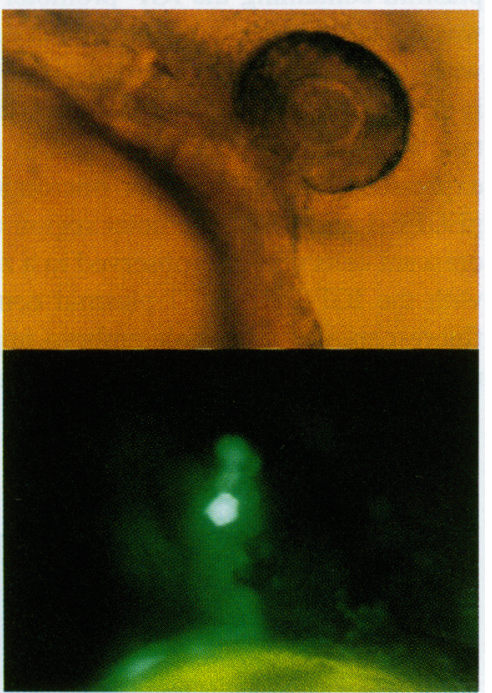

FIG. 9. The $I G F-I I$ promoter-GFP vector microinjected into zebrafish 2-cell-stage fertilized eggs. Fluorescence (bottom) and brightfield (top) photographs. A. The GFP was first visibly expressed at $8 \mathrm{~h}$ (75\% epiboly, gastrula period). Photograph was taken with $100 \times$ lens on Olympus microscope IX70. The $I G F-I I$ promoter-GFP vector was highly expressed from embryo to embryo (B) and from 1 stage to the next (panel $\mathrm{C}$ is $24 \mathrm{~h}$ after injection, and panel $\mathrm{D}$ is $48 \mathrm{~h}$ after injection). Panel D shows two fish of which the upper was not injected. Green fluorescence accumulated in yolk sac, yolk sac extension, and notochord (D). The GFP is visible in horizontal myoseptum (E), eye (F), and floor plate $(\mathrm{G}) 48 \mathrm{~h}$ after microinjection. 
[19.2 \pm 2.3$]$ and IGF-II P8 $\leftarrow$ P11 $[24.4 \pm 2.9])$ produced lower promoter activity than was seen with the fragment of IGFII P7 $\rightarrow$ P11 and the other fragment. These results show that the sequence from IGF-II P5 $\rightarrow$ P6 contains a negative regulatory element, and the sequence from IGF-II P6 $\rightarrow$ P7 contains a positive regulatory element. The sequence from IGF-II P5 $\rightarrow$ P6 contains a possible Spl-binding regulatory element. This putative Sp1 element may play an important role in regulating $I G F-I I$ promoter function in tilapia.

\section{Expression of IGFs promoter-GFP in human cell line and zebrafish embryos}

To understand the $I G F$ s promoter regulation in fish, we constructed the fragment IGF-I P2 $\rightarrow$ P7 and the fragment IGF-II $\mathrm{P} 5 \rightarrow \mathrm{P} 11$ ligated with the pEGFP-1 vector. The promoter activity of these regions produces enzymatic activity to a maximum value identified by transient transfection expression in human lung large cell carcinoma cells, as described above. A plasmid containing the $I G F$ promoter driving the $G F P$ cDNA was transfected into lung carcinoma cells, and the fluorescence was observed (Fig. 7). The data show that the IGF-II promoter is stronger than the $I G F-I$ promoter, and the fish promoter can take advantage of the GFP system in the human cell line to be expressed. About $24 \mathrm{~h}$ after microinjection of the plasmid of pEGFP-1 and $I G F-I$ promoter region construct, patches of fluorescent cells could be observed in a zebrafish embryo injected with the IGF-I P2 $\rightarrow$ P7 plasmid construct (Fig. 8). The low fluorescence in the whole embryo implies that the IGF-I promoter has little expression during the zebrafish straightening

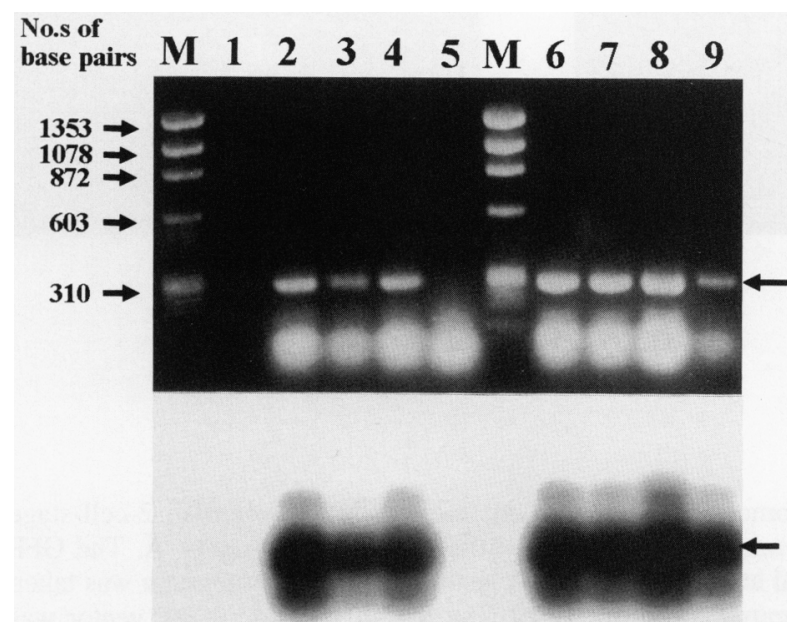

FIG. 10. Detection of $I G F-I$ (lane 1 to lane 5) and $I G F-I I$ (lane 6 to lane 9) promoters driving GFP cDNA production of mRNA in each stage of embryos and fish (Brachydanio rerio). Whole-embryo total RNA and juvenile tilapia total RNA were extracted, and RT-PCR and Southern blot analyses were conducted as described in the text. Upper picture shows ethidium bromide staining of RT-PCR products using GFP-specific primers. Lower picture shows Southern blot analysis of the gel using ${ }^{32} \mathrm{P}$-labeled GFP full-length cDNA as a probe. Lane $\mathrm{M}$ is $\phi$ X174 HaeIII marker. Lanes 1 and 6: 32-cell stage; lanes 2 and 7: 1-K-cell stage; lanes 3 and $8: 30 \%$ epiboly stage; lane 4: gastrula stage; lane 5: 1-wk-old fish; lane 9: 2-wk-old fish. period. Otherwise, $8 \mathrm{~h}$ (75\% epiboly, gastrula period; Fig. 9A) after injection of the plasmid of pEGFP-1 and $I G F-I I$ promoter construct, patches of fluorescent cells could be observed in 42 of the 60 embryos. Strongly fluorescent cells were visible from embryo to embryo (Fig. 9B) and from one stage to the next (Fig. 9C, D). The fluorescence was visible for up to $1 \mathrm{wk}$; in $24 \mathrm{~h}$, it was visible in the horizontal myoseptum and the eye (Fig. 9E, F); in $48 \mathrm{~h}$, the fluorescence appeared in the yolk sac (Fig. 9D) and floor plate (Fig. 9G). The fluorescence from the segmentation period to the straightening period also appeared in the heart and blood cells (data not shown). The expression of Xex-GFP in zebrafish embryos appears in a pattern different from what was seen in our studies (Amsterdam et al., 1995).

After injection of the fragment IGF-I P2 $\rightarrow$ P7 and the fragment IGF-II P5 $\rightarrow$ P11 ligated with pEGFP-1 vector into zebrafish embryos, RT-PCR was run using primers GFP1 and GFP2 (see Table 1), followed by Southern blotting by hybridization assay. The data show that the tilapia $I G F-I$ promoter drives the GFP cDNA the first time the transcripts rise in the 1-K-cell period; after $1 \mathrm{wk}, \mathrm{RT}-\mathrm{PCR}$ cannot detect the tilapia $I G F-I$ promoter-driven transcript products (Fig. 10). In IGF-II, the promoter drives the GFP cDNA the first time the transcripts rise in the 32-cell period; after $2 \mathrm{wk}$, the RT-PCR can continuously detect the $I G F-I I$ promoter-driven transcript products, but expression is weak (Fig. 10).

\section{DISCUSSION}

The tilapia IGF-I cDNA insert contains 549 nt, which encode 183 amino acid residues. In the tilapia $\mathrm{E}$ domain, there are 11 amino acid insertions. The IGF-I has four size forms, and the size differences are attributable to insertions or deletions of E-domain amino acids (Chen et al., 1994). According to the insertions or deletions, the $I G F-I$ forms are designated Ea-1, Ea-2, Ea-3, or Ea-4 (Duguay et al., 1992; Holthuizen et al., 1991; Shamblott and Chen, 1993). Tilapia IGF-I RT-PCR products belong to Ea-4. The IGF-I Ea-4 form is also found in coho salmon (Duguay et al., 1992), rainbow trout (Shamblott and Chen, 1993), and chinook salmon (Wallis and Devlin, 1993). The quantity of Ea-4 mRNA was not changed after GH treatment, and the Ea-4 transcript was expressed only in most nonhepatic tissues (Duguay et al., 1994). In our experiment, the first step was to inject $\mathrm{GH}$ to induce high expression of IGF-I. Growth hormone can increase immunoreactive IGF-I levels in fish plasma and mRNA levels of IGF-I in salmon liver. Gillichthys mirabilis was injected with tilapia $\mathrm{GH}$, and it has been suggested that IGF-I is sensitive to the GH status of the animal (Gray and Kelley 1991). Plasma IGF-I levels increased significantly after $48 \mathrm{~h}$ in Oncorhynchus mykiss injected with a higher dose of GH (Moriyama et al., 1995).

Figure 2 shows that the mature tilapia IGF-I peptide has nine amino acids different from the conjectured ancestral piscine peptide. They are located at B26(Asn), C6(Cys), A14(Gln), D4(Thr), D5(Pro), D7(Ile), and D8(Ser). The peptide changes include SerB26(Asn $\rightarrow$ Ser) and AlaD8(Ser $\rightarrow$ Ala), but the other five amino acids could not be distinguished from the conjectured ancestral peptide. Compared with the ancestral piscine IGF-I, the tilapia IGF-I B26 was changed to a polar amino acid (Asn), but ArgA14 was changed to a charged GlnA14, and hy- 
drophobic AlaD8 was changed to a SerD8. The implications for the protein structure and stereospecific form of the two changes here are still unknown. The human native IGF-I molecule contains three disulfide bonds linking six cysteine residues. They are located at CysB6-CysA7, CysA6-CysA11, and CysB18CysA20 (Iwai et al., 1989); in tilapia, the linking disulfide bonds are located at the same sites. In the $\mathrm{C}$ domain, HisC10 and $\mathrm{AsnC} 11$ exist in rainbow trout, salmon, hagfish, and catfish but have been deleted in tilapia. In the E domain, the actual mechanism is at present unknown. The N-linked glycosylation site (Asn-X-Ser/Thr) exists at the amino acid position E22-24 in humans, while the rat and mouse also have a glycosylation site at E30-E32 (Howard and Charles, 1991). In contrast, the tilapia sequences contain a putative glycosylation site at residues E57-E59 (see Fig. 1). In the E peptide processing site there is a Lys-Lys-Lys motif. Chum salmon IGF-I.1 and IGF-I.2 sequences have Pro and Thr instead of Lys (Kavsan et al., 1994), but in tilapia, the possible motif is an Asn-Lys-Lys sequence. The actual physiological role of this sequence in tilapia is unknown. Comparing this with the known sequences in other fish species shows that fish IGF-Is are highly conserved.

We have sequenced and identified $I G F-I$ and $I G F-I I$ proximal promoter regions in the tilapia $I G F s$ gene. In the chicken, the $I G F-I$ gene is about $50 \mathrm{~kb}$ in length (Kajimoto and Rotwein, 1991), and those of rat and human genes are from 80 to $100 \mathrm{~kb}$ (Rotwein et al., 1986; Shimatsu and Rotwein, 1987). If the tilapia $I G F-I$ gene is the same length as the chum salmon gene, then, compared with avian and mammalian $I G F-I$ genes, the fish gene is very small. In tilapia, in contrast to the salmon IGFI gene (Koval et al., 1994), there is a TATA-like consensus sequence upstream of the first methionine to about $300 \mathrm{bp}$. The vicinity of the tilapia $I G F-I$ proximal promoter sequence contains a potential hepatocyte nuclear factor 1 (HNF-1) and hepatocyte nuclear factor 5 (HNF-5) binding site; however the HNF-1-binding site sequence is identical in chum salmon $(\mathrm{Ku}-$ lik et al., 1995) and is also found in the Sparus aurata IGF-I genomic sequence (Funkenstein et al., 1996).

Here, we confirm that the tilapia IGF-I gene contains five exons. Tilapia exon 4 is the same as the mammalian exon 5 (Holthuizen et al., 1991). Tilapia exon 4 is a "cassette" exon; the cassette is retained in some IGF-I mRNAs but not in others. There are "cassette" exons retained in mRNA termed Eb IGF-I mRNAs, otherwise termed Ea IGF-I mRNAs. The two types of IGF-I prepropeptides (IGF-I Ea and $\mathrm{Eb}$ ) give rise to the alternative splicings. In rats, the two types, IGF-I Ea and Eb, depend on whether the differential splicing contains the 52nt mini-exon (Adamo et al., 1991), and in rats, the mini-exon is suggested to cause a frameshift and the introduction of a stop codon. In chinook salmon, four distinct $I G F-I$ genes were found by Southern blotting, which suggests that there are at least two IGF-I loci in salmon (Wallis and Devlin, 1993). In tilapia, this remains unknown, although we have performed Southern blotting in this species. In chum salmon, there are two nonallelic IGF-I genes (Kavsan et al., 1994), but in tilapia, we have not yet obtained this sequence.

Analysis of the tilapia $I G F-I I$ proximal promoter region sequence has shown possible transcription factor-binding elements such as Sp1. The human IGF-II $\mathrm{P} 4$ promoter shows several $\mathbf{G}+\mathrm{C}$-rich regions and three possible Spl-binding sequences (Hyun et al., 1993). In the rat, the results suggest that there are four proximal upstream GC boxes binding the general transcription factor Sp1 (Soares et al., 1986; Evans $e t$ al., 1988). Comparison of the tilapia $I G F-I I$ proximal promoter region upstream of the first methionine DNA sequence with those of the human and rat indicates that homology is low among the three species. The potential transcription factor-binding sequence represents only an Sp1 site but does not include an Egr-1 site in the tilapia $I G F-I I$ proximal promoter region. The tilapia last exon shows a poly(AT) stretch different from the human poly(AC) stretch (de Pagter-Holthuizen et al., 1988). Additional IGF-II transcripts of between 1.2 and $3.0 \mathrm{~kb}$ have been detected in fetal rat tissue and transformed cells, but their origins are unclear. A stable 1.8-kb RNA is formed that is derived from the $3^{\prime}$ untranslated region of exon 9; this RNA is formed through site-specific endonucleolytic cleavage of IGFII mRNAs (Meinsma et al., 1992; Nielsen and Christiansen, 1992). Unusually, cleavages of the IGF-II mRNA trailer will occur at a guanosine-rich region and a putative hairpin (Meinsma et al., 1992; Nielsen and Christiansen, 1992). The poly(AT) stretch of the tilapia last exon was shown to play an important role in gene regulation of general mechanisms of mRNA degradation; alternatively, specific mRNAs may be selectively targeted for degradation (Ratnasabapathy et al., 1990).

The CAT analyses presented here suggest that the tilapia $I G F-I$ promoter's more distal 5' flanking region has greater activity (IGF-I P2 $\rightarrow \mathrm{P} 7$ ). In rat IGF-I, exon 2 transcripts are expressed at high levels in the OVCAR-3 cell line (Tobin et al., 1990; Yee et al., 1991). The construction containing 1500 bp of $5^{\prime}$ flanking sequence and 44 bp of exon 2 stimulates luciferase activity 13- to 23-fold, whereas the fragment containing only 36 bp of the $5^{\prime}$ flanking sequence is inactive (Wang et al., 1997). In tilapia, if the fragment is shortened to $132 \mathrm{bp}$ (IGF-I P5 $\rightarrow$ P4), the activity is weak $(13.6 \pm 2.2)$. When the tilapia $I G F-I I$ proximal promoter region is shortened to $450 \mathrm{bp}$ (IGF-II P5 $\rightarrow$ P11), it shows maximum activity. The fragment IGF-II P5 $\rightarrow$ P6 shows a negative regulatory effect, and the fragment IGF-II P6 $\rightarrow$ P7 shows a positive regulatory effect. The fragment IGF-II P5 $\rightarrow$ P6 shows a putative Sp1 transcription factor-binding element. Here, Spl may play a negative regulatory role, but in humans, Sp1 binds to the P4 promoter and is involved in regulation of the transcription of the $I G F-I I$ gene (Hyun et al., 1993).

Salmon $I G F-I$ genes have negative regulatory effects that may be due to the tissue-specific and developmental regulation of $I G F-I$ gene expression (Koval et al., 1993). Human IGF-II mRNAs show transcription can be initiated at three distinct promoter sites, suggesting that these promoters may be subject to tissue-specific and development-specific regulation (de PagterHolthuizen et al., 1987, 1988). To integrate these reports, we can say that the $I G F s$ promoter is regulated by a complicated pathway. To understand IGFs promoter function, we used the GFP system as a reporter gene (Amsterdam et al., 1995; Ogawa et al., 1995; Chiu et al., 1996; Corbo et al., 1997). In the analyses presented here, GFP mRNA was detected using primers designed to amplify GFP cDNA specifically, and the result was confirmed by Southern blot analysis. In rainbow trout, the early detection in embryos of IGFs mRNA expression is similar to that in bovine embryos (Telford et al., 1990; Schultz and Heyner, 1992; Schultz et al., 1993; Greene and Chen, 1997). 
However, those reports could not confirm the presence of mature IGF peptides in embryos. In our GFP system, the IGFs proximal promoter drove the GFP cDNA, which then produced the GFP protein, and fluorescence could be observed. In other words, the construction of GFP cDNA is replaced by the IGF coding region of genomic DNA sequences. When the promoter starts to drive, the mature IGF peptide may be present in the natural state of the fish. From our GFP analysis data, we found that the $I G F-I I$ proximal promoter was expressed more strongly than was the $I G F-I$ proximal promoter in the embryo stage and began expression earlier than did $I G F-I$. Although we used RTPCR to check GFP transcripts, we found that $I G F-I$ proximal promoter-driven GFP transcripts appeared for the first time at the 1-K cell stage, and the $I G F-I I$ proximal promoter-driven GFP transcripts appeared for the first time at the 32-cell stage. These data will need further checking in the next generation of IGF promoter-GFP transgenic fish. The IGFs proximal promoter may play an important role in teleost embryos for controlling IGF expression.

In summary, we have located two 5' cDNA termini in tilapia $I G F-I$ and one in tilapia $I G F-I I$ using the 5'RACE method. We have determined the proximal promoter region in the tilapia IGFs gene using CAT analysis and have presented GFP and GFP/RT-PCR data suggesting that the fish $I G F s$ first proximal promoter region plays a very important role in controlling IGF expression in embryo development. Future studies will focus on characterization of the tilapia second promoter and on finding interactions between IGFs and specific transcription factors controlling gene expression in fish.

\section{ACKNOWLEDGMENTS}

We thank Dr. Thomas T. Chen for his advice on this manuscript and Dr. Wei-Yuan Chow for kindly providing the Oreochromis mossambicus genomic DNA library. We thank Dr. Ching-Ming Kuo, Dr. Mau-Sun Chang, and Dr. Cho-Fat Hui for valuable advice and scientific discussions. We thank Dr. IChiu Liao for his support and encouragement. This work was supported by NSC Grants NSC87-2311-B-001-031-B24 (R.O.C). to Dr. Jen-Leih Wu.

\section{REFERENCES}

ADAMO, M.L., BEN-HUR, H., ROBERTS, C.T., JR, and LEROITH, D. (1991). Regulation of start site usage in the leader exons of the rat insulin-like growth factor-I gene by developments, fasting, and diabetes. Mol. Endocrinol. 5, 1677-1686.

AMSTERDAM, A., LIN, S., and HOPKINS, N. (1995). The Aequorea victoria green fluorescent protein can be used as a reporter in live zebrafish embryos. Dev. Biol. 171, 123-129.

AMSTERDAM, A., LIN, S., MOSS, L.G., and HOPKINS, N. (1996). Requirements for green fluorescent protein detection in transgenic zebrafish embryos. Gene 173 (Spec. Iss. 1), 99-103.

BELL, G.I., STEMPIEN, M.M., FONG, N.M., and RALL, L.B. (1986). Sequence of liver cDNA encoding two different mouse insulin-like growth factor I precursors. Nucleic Acids Res. 14, 7873-7882.

CAO, Q.P., DUGUAY, S.J., PLISENTSKAYA, E.M., STEINER, D.F., and CHAN, S.J. (1989). Nucleotide sequence and growth hormone- regulated expression of salmon insulin-like growth factor I mRNA. Mol. Endocrinol. 3, 2005-2010.

CHEN, J.Y., CHANG, C.Y., CHEN, J.C., SHEN, S.C., and WU, J.L. (1997). Production of biologically active recombinant tilapia insulinlike factor-II polypeptides in $E$. coli cells and characterization of the genomic structure of the coding region. DNA Cell Biol. 16, 883-892. CHEN, T.T., MARSH, A., SHAMBLOTT, M., CHAN, K.M., TANG, Y.L., CHENG, C., and YANG, B.Y. (1994). Structure and evolution of fish growth hormone and insulin-like growth factor genes. In $\mathrm{Mol}$ ecular Endocrinology of Fish, Fish Physiology, Vol. XIII. N.M. Sherwood, and C.L. Hew, eds. (Academic Press, New York) pp. 179-209. CHIU, W., NIWA, Y., ZENG, W., HIRANO, T., KOBAYASHI, H., and SHEEN, J. (1996). Engineered GFP as a vital reporter in plants. Curr. Biol. 6, 325-330.

CHOMCZYNSKI, P., and SACCHI, N. (1987). Single-step method of RNA isolation by acid guanidinium thiocyanate-phenol-chloroform extraction. Anal. Biochem. 162, 156-159.

CLEMMONS, D.R., and UNDERWOOD, L.E. (1991). Nutritional regulation of IGF-I and IGF binding protein. Annu. Rev. Nutr. 11, 383-412.

CONOVER, C.A., BAKER, B.K., BALE, L.K., CLARKSON, J.T., LIU, F., and HINTZ, R.L. (1993). Human hepatoma cells synthesize and secrete insulin-like growth factor Ia prohormone under growth hormone control. Regul. Pep. 48, 1-8.

CORBO, J.C., LEVINE, M., and ZELLER, R.W. (1997). Characterization of a notochord-specific enhancer from the Brachyury promoter region of the ascidian, Ciona intestinalis. Development 124, 589-602.

CZECH, M.P., LEWIS, R.E., and CORVORA, S. (1989). Multifunctional glycoprotein receptors for insulin and the insulin-like growth factors. CIBA Found. Symp. 145, 27-44.

DAUGHADAY, W.H., and ROTWEIN, P. (1989). Insulin-like growth factor I and II: peptide, messenger ribonucleic acid and gene structure, serum, and tissue concentrations. Endocr. Rev. 10, 68-91.

DE PAGTER-HOLTHUIZEN, P., JANSEN, M., VAN SCHAIK, F.M.A., VAN DER KAMMEN, R.A., OOSTERWIJK, C., VAN DEN BRANDE, J.L., and SUSSENBACH, J.S. (1987). The human insulin-like growth factor II contains two development-specific promoters. FEBS Lett. 214, 259-264.

DE PAGTER-HOLTHUIZEN, P., JANSEN, M., VAN DER KAMMEN, R.A., VAN SCHAIK, R.M.A., and SUSSENBACK, J.S. (1988). Differential expression of the human IGF-II gene: characterization of the IGF-II mRNAs and an mRNA encoding a putative IGF-II associated protein. Biochim. Biophys. Acta 950, 282-295.

DICKSON, M.C., SAUNDERS, J.C., and GILMOUR, R.S. (1991). The ovine insulin-like growth factor-I gene: characterization, expression and identification of a putative promoter. J. Mol. Endocrinol. 6, 17-31.

DRAKENBER, K., SARA, V.R., LINDAHL, K.I., and KEWISH, B. (1989). The study of insulin-like growth factors in tilapia, Oreochromus mossambicus. Gen. Comp. Endocrinol. 74, 173-180.

DUGUAY, S.J., PARK, L.K., SAMADPOUR, M., and DICKHOFF, W.W. (1992). Nucleotide sequence and tissue distribution of three insulin-like growth factor I prohormones in salmon. Mol. Endocrinol. 6, 1202-1210.

DUGUAY, S.J., SWANSON, P., and DICKHOFF, W.W. (1994). Differential expression and hormonal regulation of alternatively spliced IGF-I mRNA transcripts in salmon. J. Mol. Endocrinol. 12, 25-37. DUGUAY, S.J., LAI-ZHANG, J., STEINER, D.F., FUNKENSTEIN, B., and CHAN, S.J. (1996). Developmental and tissue-regulated expression of IGF-I and IGF-II mRNAs in Sparus aurata. J. Mol. Endocrinol. 16, 123-132.

EVANS, T., DECHIARA, T., and EFSTRATIADIS, A. (1988). A promoter of the rat insulin-like growth factor II gene consists of minimal control elements. J. Mol. Biol. 1988, 61-81.

FROHMAN, M.A. (1990). PCR Protocols: A Guide to Methods and 
Applications M.A. Innis, D.H. Gelfand, J. Sninsky, and T.J. White, eds. (Academic Press, San Diego), p. 28.

FROHMAN, M.A. (1993). Rapid amplification of complementary DNA ends for generation of full-length complementary DNAs: thermal RACE. Methods Enzymol. 218, 340-356.

FUNKENSTEIN, B., SHEMER, R., AMULY, R., and COHEN, I. (1996). Nucleotide sequence of the promoter region of Sparus aurata insulin-like growth factor I gene and expression of IGF-I in eggs and embryos. Mol. Mark. Biol. Biotechnol. 5, 43-51.

GRAY, E.S., and KELLEY, K.M. (1991). Growth regulation in the gobiid teleost, Gillichthys mirabilis: roles of growth hormone, hepatic growth hormone receptors and insulin-like growth factor-I. J. Endocrinol. 131, 57-66.

GREENE, M.W., and CHEN, T.T. (1997). Temporal expression pattern of insulin-like growth factor mRNA during embryonic development in a teleost, rainbow trout (Onchorynchus mykiss). Mol. Mark. Biol. Biotechnol. 6, 144-151.

HALL, L.J., KAJIMOTO, Y., BICHELL, D., KIM, S.W., JAMES, P.L., COUNTS, D., NIXON, L.J., TOBIN, G., and ROTWEIN, P. (1992). Functional analysis of the rat insulin-like growth factor-I gene and identification of an IGF-I gene promoter. DNA Cell Biol. 11, 301-313.

HIGGINS, D.G., and SHARP, P.M. (1988). CLUSTAL: a package for performing multiple sequence alignment on a microcomputer. Gene 73, 237-244.

HOLTHUIZEN, P., VAN DER LEE, F.M., IKEJIRI, K., YAMAMOTO, M., and SUSSENBACH, J.S. (1990). Identification and initial characterization of a fourth leader exon and promoter of the human IGF-II gene. Biochim. Biophys. Acta 1087, 341-343.

HOLTHUIZEN, E., LEROITCH, D., LUND, P.K., ROBERTS, C.T. JR., ROTWEIN, P., SPENCER, E.M., and SUSSENBACH, J.S. (1991). Revised nomenclature for the insulin-like growth factor genes and transcripts. In Modern Concepts of Insulin-Like Growth Factors. E.M. Spencer, ed. (Elsevier, New York).

HOWARD, L.F. and CHARLES T.R. JR. (1991). The IGF-I gene: structure, expression, and gene products. In Insulin-Like Growth Factor: Molecular and Cellular Aspects. D. LeRoith, ed. (CRC, Boca Raton, FL) pp. 1-16.

HYUN, S.W., KIM, S.J., PARK, K., RHO, H.M., and LEE, Y.I.K. (1993). Characterization of the $P 4$ promoter region of the human insulin-like growth factor-II gene. FEBS Lett. 332, 153-158.

IKEJIRI, K., UENO, T., MATSUGUCHI, T., TAKAHASHI, K., ENDO, H., and YAMAMOTO, M. (1990). The primary structure of the rat insulin-like growth factor II gene region. Biochim. Biophys. Acta 1049, 350-353.

IKEJIRI, K., FURUICHI, M., UENO, T., MATSUGUCHI, T., TAKAHASHI, K., ENDO, H., and YAMAMOTO, M. (1991). The presence and active transcription of three independent leader exons in the mouse insulin-like growth factor II gene. Biochim. Biophys. Acta 1089, 77-82.

IWAI, M., KOBAYASHI, M., TAMURA, K., ISHII, Y., YAMADA, H., and NIWA, M. (1989). Direct identification of disulfide bond linkages in human insulin-like growth factor I (IGF-I) by chemical synthesis. J. Biochem. Tokyo 106, 949-951.

KAJIMOTO, Y., and ROTWEIN, P. (1991). Structure of the chicken insulin-like growth factor I gene reveals conserved promoter elements. J. Biol. Chem. 266, 9724-9731.

KAVSAN, V.M., KOVAL, A.P., GREBENJUK, V.A., CHAN, S.J., STEINER, D.F., ROBERTS, C.T. JR., and LEROITH, D. (1993). Structure of the chum salmon insulin-like growth factor-I gene. DNA Cell Biol. 12, 729-737.

KAVSAN, V.M., GREBENJUK, V.A., KOVAL, A.P., SKOROKHOD, A.S., ROBERTS, C.T. JR., and LEROITH, D. (1994). Isolation of a second nonallelic insulin-like gene growth factor I gene from the salmon genome. DNA Cell Biol. 13, 555-559.
KIM, S.W., LAJARA, R., and ROTWEIN, P. (1991). Structure and function of a human insulin-like growth factor I gene promoter. Mol. Endocrinol. 5, 1964-1972.

KLAPPER, D.C., SVOBODA, M.E., and VAN WYK, J.J. (1983). Sequence analysis of somotomedin-C: confirmation of identity with insulin-like factor I. Endocrinology 112, 2215-2217.

KOVAL, A., KULIK, V., DUGUAY, S., PLISETSKAYA, E., ADAMO, M.L., ROBERTS, C.T. JR., LEROITH, D., and KAVSAN, V. (1994). Characterization of a salmon insulin-like growth factor I promoter. DNA Cell Biol. 13, 1057-1062.

KULIK, V.P., KAVSAN, V.M., VANSCHAIK, F.M., NOLTEN, L.A., STEENBERGH, P.H., and SUSSENBACH, J.S. (1995). The promoter of the salmon insulin-like growth factor I gene is activated by hepatocyte nuclear factor I. J. Biol. Chem. 270, 1068-1073.

KUMAR, S., TAMURA, K., and NEI, M. (1993). MEGA: Molecular Evolutionary Genetics Analysis, Version 1.01. (The Pennsylvania State University, University Park, PA 16802).

LEROITH, D., KAVSAN, V.M., KOVAL, A.P., and ROBERTS, C.T. JR. (1993). Phylogeny of the insulin-like growth factors (IGFs) and receptor: a molecular approach. Mol. Reprod. Dev. 35, 332-338.

LIANG, Y.H., CHENG, C.H.K., and CHAN, K.M. (1996). Insulin-like growth factor IEa2 is the predominantly expressed form of IGF in common carp (Cyprinus carpio). Mol. Mark. Biol. Biotechnol. 5, 145-152.

MATHEWS, L.S., NORSTEDT, G., and PALMITER, R.D. (1986). Regulation of insulin-like growth factor I gene expression by growth hormone. Proc. Natl. Acad. Sci. USA 83, 9343-9347.

MCRORY, J.E., and SHERWOOD, N.M. (1994). Catfish express two forms of insulin-like growth factor-I (IGF-I) in the brain: ubiquitous IGF-I and brain-specific IGF-I. J. Biol. Chem. 269, 18588-18592.

MEINSMA, D., SCHEPER, W., HOLTHUIZEN, P.E., VAN DEN BRANDE, J.L., and SUSSENBACH, J.S. (1992). Site-specific cleavage of IGF-II mRNAs requires sequence elements from two distinct regions of the IGF-II gene. Nucleic Acids Res. 20, 5003-5009.

MORIYAMA, S., DICKHOFF, W.W., and PLISETSKAYA, E.M. (1995). Isolation and characterization of insulin-like growth factor-I from rainbow trout, Oncorhynchus mykiss. Gen. Comp. Endocrinol. 99, 221-229.

MULLER, M. and BREM, G. (1990). Nucleotide sequence of porcine insulin-like growth factor I: $5^{\prime}$-untranslated region, exon1 and exon2 and mRNA. Nucleic Acids Res. 18, 364.

NAGAMASU, S., CHAN, S.J., FALKMER, S., and STEINER, D.F. (1991). Evolution of the insulin gene superfamily: sequence of a prepro insulin-like growth factor cDNA from the Atlantic hagfish. J. Biol. Chem. 266, 2397-2402.

NIELSEN, F.C. and CHRISTIANSEN, J. (1992). Endonucleolysis in the turnover of insulin-like growth factor II mRNA. J. Biol. Chem. 267, 19404-19411.

OGAWA, H., INOUYE, S., TSUJI, F.I., YASUDA, K., and UMESONO, K. (1995). Localization, trafficking, and temperaturedependence of the Aequorea green fluorescent protein in cultured vertebrate cells. Proc. Natl. Acad. Sci. USA 92, 11899-11903.

OHLSEN, S.M., LUGENBEEL, K.A., and WONG, E.A. (1994). Characterization of the linked ovine insulin and insulin-like growth factor II genes. DNA Cell Biol. 13, 377-388.

PEDUEL, A.D., ELIZUR, A., and KNIBB, W. (1994). Cloning and sequencing of dolphinfish (Coryphaena hippurus, Coryphaenidae) growth hormone encoding cDNA. DNA Seq. 5, 121-123.

RATNASABAPATHY, R., HWANG, S.P.L., and WILLIAMS, D.L. (1990). The 3'-untranslated region of apolipoprotein II mRNA contains two independent domains that bind distinct cystosolic factors. J. Biol. Chem. 265, 14050-14055.

RINDERNECHT, E. and HUMBEL, R.E. (1978). The amino acid sequence of human insulin-like growth factor $I$ and its structural homology with proinsulin. J. Biol. Chem. 253, 2769-3706. 
ROBERTS, C.T. JR., LASKY, S.R., LOWE, W.L. JR., and LEROITH, D. (1987). Rat IGF-I cDNAs contain multiple 5 '-untranslated regions. Biochem. Biophys. Res. Commun. 146, 1154-1159.

ROTWEIN, P., POLLOCK, K.M., DIDIER, D.K., and KRIVI, G.G. (1986). Organization and sequence of the human insulin-like growth factor I gene: alternative RNA processing produces two insulin-like growth factor I precursor peptides. J. Biol. Chem. 261, 4828-4832.

ROTWEIN, P., and HALL, L.J. (1990). Evolution of IGF-II: characterization of the mouse IGF-II gene and identification of two pseudoexons. DNA Cell Biol. 9, 725-735.

SANGER, F., NICKLEN, S., and COULSON, A.R. (1992). DNA sequencing with chain-terminating inhibitors. 1977 [classical article] Biotechnology 24, 104-108.

SCHULTZ, G.A., and HEYNER, S. (1992). Gene expression in preimplantation mammalian embryos. Mutat. Res. 296, 17-31.

SCHULTZ, G.A., HAHNEL, A., ARCELLANA-PANLILIO, M., WANG, L., GOUBAU, S., WATSON, A., and HARVEY, M. (1993). Expression of IGF ligand and receptor genes during preimplantation mammalian development. Mol. Reprod. Dev. 35, 414-420.

SHAMBLOTT, M.J., and CHEN, T.T. (1992). Identification of a second insulin-like growth factor in a fish species. Proc. Natl. Acad. Sci. USA 89, 8913-8917.

SHAMBLOTT, M.J., and CHEN, T.T. (1993). Age-related and tissuespecific levels of five forms of insulin-like growth factor mRNA in a teleost. Mol. Mark. Biol. Biotechnol. 2, 351-361.

SHIMATSU, A., and ROTWEIN, P. (1987). Mosaic evolution of the insulin-like growth factors: organization, sequence, and expression of the rat insulin-like growth factor I gene. J. Biol. Chem. 262, 7894-7900.

SOARES, M.B., TURKEN, A., ISHII, D., MILLS, L., EPISKOPOU, V., COTTER, S., ZEITLIN, S., and EFSTRATIADIS, A. (1986). Rat insulin-like growth factor II gene: a single gene with two promoters expressing a multitranscript family. J. Mol. Biol. 192, 737-752.

TELFORD, N.A., WATSON, A.J., and SCHULTZ, G.A. (1990). Transition from maternal to embryonic control in early mammalian development: a comparison of several species. Mol. Reprod. Dev. 26, 90-100.
TOBIN, G., YEE, D., BRUENNER, N., and ROTWEIN, P. (1990). A novel human insulin-like growth factor $\mathrm{I}$.

TSAI, H.J., LIN, K.L., and CHEN, T.T. (1993). Molecular cloning and expression of yellowfin porgy (Acanthopagrus latus Houttuyn) growth hormone cDNA. Comp. Biochem. Physiol. 104B, 803-810.

TSAI, H.L., KOU, G.H., CHEN, S.C., WU, C.W., and LIN, Y.S. (1996). Human cytomegalovirus immediate-early protein IE2 tethers a transcriptional repression domain to p53. J. Biol. Chem. 271, 3534-3540.

WALLIS, A.E., and DEVLIN, R.H. (1993). Duplicate insulin-like growth factor-I genes in salmon display alternative splicing pathways. Mol. Endocrinol. 7, 409-422.

WANG, X., YANG, Y., and ADAMO, M.L. (1997). Characterization of the rat insulin-like growth factor I gene promoters and identification of a minimal exon 2 promoter. Endocrinology 138, 1528-1536.

WINKLER, C., VIELKIND, J.R., and SCHARTL, M. (1991). Transient expression of foreign DNA during embryonic and larval development of the medaka fish (Oryzias latipes). Mol. Gen. Genet. 226, 129-140.

WONG, E.A., OLLSEN, S.M., GODFREDSON, J.A., DEAN, D.M., and WHEATON, J.E. (1989). Cloning of ovine insulin-like growth factor-I cDNAs: heterogeneity in the mRNA population. DNA 8, 649-657.

Address reprint requests to: Dr. Jen-Leih Wu Institute of Zoology Academia Sinica Nankang, Taipei, Taiwan 11529 The Republic of China

Received for publication August 29, 1997; accepted November 24, 1997. 